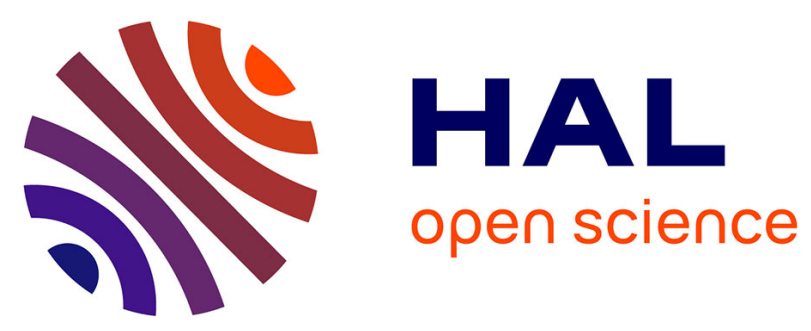

\title{
Deformation modes during room temperature tension of fine-grained pure magnesium
}

Zhuoran Zeng, Mengran Zhou, Peter Lynch, Frédéric Mompiou, Qinfen Gu, Mohsen Esmaily, Yuanming Yan, Yao Qiu, Shiwei Xu, Hidetoshi Fujii, et al.

\section{- To cite this version:}

Zhuoran Zeng, Mengran Zhou, Peter Lynch, Frédéric Mompiou, Qinfen Gu, et al.. Deformation modes during room temperature tension of fine-grained pure magnesium. Acta Materialia, 2021, 206 (1), pp.116648. 10.1016/j.actamat.2021.116648 . hal-03380274

\section{HAL Id: hal-03380274 https://hal.science/hal-03380274}

Submitted on 19 Oct 2021

HAL is a multi-disciplinary open access archive for the deposit and dissemination of scientific research documents, whether they are published or not. The documents may come from teaching and research institutions in France or abroad, or from public or private research centers.
L'archive ouverte pluridisciplinaire HAL, est destinée au dépôt et à la diffusion de documents scientifiques de niveau recherche, publiés ou non, émanant des établissements d'enseignement et de recherche français ou étrangers, des laboratoires publics ou privés. 


\title{
Deformation modes during room temperature tension of fine-grained pure magnesium
}

\author{
Zhuoran Zeng ${ }^{\mathrm{a}, \mathrm{b}}, *$, Mengran Zhou ${ }^{\mathrm{c}, \mathrm{d}}$, Peter Lynch ${ }^{\mathrm{e}}$, Frédéric Mompiou ${ }^{\mathrm{f}}$, Qinfen Gu ${ }^{\mathrm{g}}$, Mohsen Esmaily ${ }^{\mathrm{b}, \mathrm{h}}$, \\ Yuanming Yan ${ }^{b}$, Yao Qiu ${ }^{b}$, Shiwei Xu ${ }^{i}$, Hidetoshi Fujii ${ }^{c}$, Chris Davies ${ }^{j}$, Jian-Feng Nie ${ }^{b}$, Nick Birbilis ${ }^{a}$ \\ a College of Engineering and Computer Science, Australian National University, ACT. 2601, Australia \\ ${ }^{\mathrm{b}}$ Department of Materials Science and Engineering, Monash University, Vic. 3800, Australia \\ c Joining and Welding Research Institute (JWRI), Osaka University, Osaka, 565-0871, Japan \\ d State Key Laboratory of Tribology, Key Laboratory for Advanced Materials Processing Technology, Department of Mechanical Engineering, Tsinghua University, Beijing, 100084, China \\ e Deakin University, Geelong, Vic. 3216, Australia \\ f CEMES-CNRS, Université de Toulouse, 29 rue J. Marvig, Toulouse, 31055, France \\ $\mathrm{g}^{\mathrm{A}}$ Australian Synchrotron, ANSTO, Clayton, Vic. 3168, Australia \\ ${ }^{\mathrm{h}}$ Department of Materials Science and Engineering, Massachusetts Institute of Technology, Cambridge, MA 02139, USA \\ i State Key Laboratory of Advanced Design and Manufacturing for Vehicle Body, Hunan University, Changsha, 410082, China \\ j Department of Mechanical and Aerospace Engineering, Monash University, Vic. 3800, Australia
}

\section{A R T I C LE IN F O}

\section{Article history:}

Received 6 June 2020

Received in revised form 29 November 2020

Accepted 10 January 2021

Available online xxx

\section{Keywords}

Magnesium

ductility

cooperative grain boundary sliding

grain rotation

recovery

\begin{abstract}
A B S T R A C T
Extruded polycrystalline pure magnesium $(\mathrm{Mg})$ with fine grain size $(\sim 1.2 \mu \mathrm{m})$ exhibits ductility of over $100 \%$ at room temperature, in spite of the presence of a strong basal texture. In this study, a set of complementary in-situ characterisation techniques over multiple-length scales were utilised to reveal the deformation modes enabling such ductility. Synchrotron X-ray diffraction results show that the elastic lattice strain of fine-grained sample for tensile elongation up to $\sim 55 \%$ is $3-10$ times lower than that in the coarse-grained sample, indicating the absence of significant strain accumulation inside fine grains and potential inter-granular deformation in bulk. In-situ scanning electron microscopy validates the predominant operation of the inter-granular deformation, and it further reveals that the inter-granular deformation occurs by the relative sliding between groups of grains having similar orientations. The deformation resulting from such sliding is substantial, and it is accommodated by the rotation of grains located between slid grouped grains, from hard to softer orientations to allowing dislocation slip to readily occur. The accommodating mode of dislocation slip is further supported by in-situ transmission electron microscopy observations. Dislocations glide readily to, and annihilate at, grain boundaries. The observations and direct evidences presented herein suggest that the major deformation mode is sliding between grouped grains that is accommodated by grain rotation and dislocation slip, in contrast to dislocation slip in coarse-grained Mg. The coordinated deformation processes postpone the occurrence of localised stress concentration and greatly increases the ductility of pure $\mathrm{Mg}$ at room temperature.
\end{abstract}

\section{Introduction}

Magnesium ( $\mathrm{Mg}$ ) is a candidate for weight-saving in the transportation and electronic industries $[1,2]$. A persistent barrier to the wider adoption of wrought Mg-alloys is their limited ductility, and hence formability, at room temperature. The intrinsically low formability of $\mathrm{Mg}$ is caused by an insufficient number of deformation modes at room temperature and a strong texture due to the hexagonal close packed (HCP) crystal structure [3]. Deformation modes in Mg include intra-granular dislocation slip on the basal, prismatic, and pyramidal planes, and twinning [4]. However, only basal slip and $\{10 \overline{1} 2\}<10$ $\overline{1} 1>$

exten-

\footnotetext{
* Corresponding author.

E-mail address: zhuoran.zeng@anu.edu.au (Z. Zeng)
}

sion twinning are the deformation modes that can be activated readily at room temperature; which are insufficient to accommodate homogeneous plastic deformation [5]. With respect to prismatic and pyramidal dislocation slip, and other modes of twinning, the required critical resolved shear stress is much higher. Compared to basal dislocation slip, they are more difficult to activate and therefore become operative at room temperature in $\mathrm{Mg}$ polycrystalline [4]. It was reported that for pyramidal II slip, even if activated, $\langle c+a\rangle$ dislocations for such a slip system dissociate into sessile dislocations that impede the migration of other mobile dislocations, resulting in high hardening and low ductility [3]. Recently, mobile $\langle c+a\rangle$ dislocation has been recorded using in-situ TEM compression of a pure $\mathrm{Mg}$ single crystal along $c$-axis [6], suggesting that $<c+a>$ dislocation slip may still contribute to the plastic deformation even in pure $\mathrm{Mg}$.

Another cause for the low ductility of $\mathrm{Mg}$ is strong basal texture, such as $[0001] / /$ normal direction (ND) in rolled sheet or $<10 \overline{1} 0>/ /$ 
extrusion direction (ED) texture, which is typically developed during thermomechanical processing. A strong basal texture makes the available basal dislocation slip even more difficult to activate and operate, leading to low formability [4]. For example, the total elongation of conventionally processed pure $\mathrm{Mg}$ is normally less than $10 \%$ [7-9]. The ductility of $\mathrm{Mg}$ at room temperature can be increased by alloying additions [4]. By adding appropriate alloying elements, e.g., rare-earth elements and zinc, the strong basal texture may be substantially weakened, allowing ready activation of basal dislocation slip, as well as non-basal dislocation slip [10]. The elongation of the resultant alloys is enhanced to $30-40 \%$ when these alloys are tensile tested at room temperature [11-15].

In addition to alloying additions, grain refinement to approximately one micron or less is another effective approach that has been used to enhance ductility, particularly for pure $\mathrm{Mg}$ and dilute (i.e. lean alloy) Mg alloys. The enhancement in ductility and formability made by this approach is so significant that samples exhibit a total elongation of more than $100 \%$ or nearly infinite compressive formability [16-23]. These findings provide a new approach for designing and developing highly formable products from $\mathrm{Mg}$ and its dilute alloys. Existing studies [18-22] proposed that the high ductility at room temperature is achieved by the occurrence of grain boundary sliding (GBS).

For metallic materials in general, GBS is regarded as a dominant mechanism when extraordinarily high ductility (elongation $>100 \%$ ) or even superplasticity (elongation $>400 \%$ ) was observed [24]. In order to activate GBS, the material must have fine grain size (initially) and deformation usually occurs at elevated temperature $\left(>0.5 \mathrm{~T}_{\mathrm{m}}\right.$, where $\mathrm{T}_{\mathrm{m}}$ is the absolute melting temperature of the material) [24]. At room temperature, the extraordinarily high ductility achieved via GBS has to date been reported in two types of metallic materials. One type is the alloys with low melting temperatures, such as $\mathrm{Bi}\left(\mathrm{T}_{\mathrm{m}}=271^{\circ} \mathrm{C}\right.$ or $544 \mathrm{~K})$ [25], and $\mathrm{Pb}\left(\mathrm{T}_{\mathrm{m}}=237 \cdot \mathrm{C}\right.$ or $\left.510 \mathrm{~K}\right)[26-28]$, $\mathrm{Zn}\left(\mathrm{T}_{\mathrm{m}}=419.5\right.$ $\cdot \mathrm{C}$ or $692.5 \mathrm{~K})[29,30]$ alloy, in which room temperature $>0.5 \mathrm{~T}_{\mathrm{m}}$ is nearly satisfied. Another approach is to form a nanocrystalline microstructure with an average grain size of several to tens of nanometres [31-33], whereby deformation is dominated by an inter-granular mechanism even at a temperature below $0.5 \mathrm{~T}_{\mathrm{m}}$ - due to a vast proportion of atoms in nanocrystalline alloys inhabiting grain boundary regions [34]. In the case of highly ductile $\mathrm{Mg}(>100 \%)$ at room temperature as reported in Refs. [18-22], however, grains are microcrystalline rather than nanocrystalline, and the deformation temperature is only $0.32 \mathrm{~T}_{\mathrm{m}}$ of $\mathrm{Mg}\left(\mathrm{Mg} \mathrm{T}_{\mathrm{m}}=923 \mathrm{~K}\left(650^{\circ} \mathrm{C}\right)\right)$, which is considerably below $0.5 \mathrm{~T}_{\mathrm{m}}$. Although trace of GBS has been observed on the surface of fine-grained $\mathrm{Mg}$ after tensile deformation at $0.32 \mathrm{~T}_{\mathrm{m}}$ [18-22], clarifying how GBS operates as a dominant deformation mode at such a (relatively) low temperature inside bulk microcrystalline $\mathrm{Mg}$ presently remains an open question. Moreover, the important evidence that supports the operation of GBS in the cited studies [18-22] is that the ductility is sensitive to strain rate, and the strain rate sensitivity values $(m)$ are around 0.2-0.3. Empirically, plastic deformation by GBS is characterised by a $m$-value of $\sim 0.5$, whilst $m=0.2-0.3$ corresponds to deformation dominated by dislocation-controlled creep, rather than GBS $[35,36]$. From this perspective, the role of GBS and dislocation slip during room temperature deformation in highly ductile $\mathrm{Mg}$ requires focused clarification. If dislocation activity is found to be a major factor, then intra-granular dislocations that are capable of resulting in ductility of $>100 \%$ at room temperature (only when the grain size is one micron or less) need to be rationalised. If GBS is the dominant mode as claimed in previous reports formability [16-23], then why the $m$-value is only $0.2-0.3$ needs to be explained. Furthermore, although the accommodation mode for GBS in fine-grained $\mathrm{Mg}$ at room temperature has been proposed $[18,19]$, the accommodation process has not been directly observed yet, and thus still needs to be further identified. Responses to such postulates are unclear, predominantly due to the lack of direct observation of the microstructural evolution during tensile testing of highly ductile polycrystalline $\mathrm{Mg}$.

To address an important knowledge gap for a technologically significant metal, a set of complementary in-situ characterisation techniques were used in this study, including in-situ synchrotron X-ray diffraction, in-situ digital image correlation (DIC), in-situ electron backscattered diffraction (EBSD), and in-situ transmission electron microscopy (TEM). The purpose of using these combined techniques is to provide a complete information on the microstructural evolution of ductile pure $\mathrm{Mg}$, covering different length scales that has not been attempted before. For the bulk material, synchrotron X-ray diffraction can reveal the evolution of elastic lattice strain and intra-granular plastic strain, which are critical for identifying the deformation mode at the macroscopic scale. Hence, pure $\mathrm{Mg}$ samples with coarse grains and with fine grains are characterised using in-situ synchrotron X-ray diffraction, in order to illustrate the impact of grain size on the deformation mechanism and importantly accumulated elastic lattice strain with applied load in the bulk material. The deformation modes revealed by the synchrotron X-ray diffraction are then cross-examined using scanning electron microscopy (SEM) based techniques at the mesoscopic scale. The in-situ SEM imaging provides surface observations about the evolution of grain size and shape, whilst the evolution of grain orientation and strain is visualised and quantified using EBSD and DIC. At the submicron or even nanoscale, in-situ TEM records the motion of dislocation and grain boundary. As mobile grain boundaries have been proposed to be important for the high ductility by accommodating GBS [35, 36], the grain boundary mobility of ductile pure $\mathrm{Mg}$ at room temperature is examined. The utilisation of combined in-situ characterisation techniques herein is expected to provide a full view of deformation modes in fine-grained $\mathrm{Mg}$ that cannot be obtained by using individual characterisation method only, allowing the mechanism of extraordinarily high ductility at room temperature in microcrystalline $\mathrm{Mg}$ to be discussed.

\section{Experimental procedures}

\subsection{Extrusion, mechanical testing and ex-situ characterisation}

Commercially pure $\mathrm{Mg}$ ingot (99.95\% from Amac Alloys, Australia) was directly extruded at $80^{\circ} \mathrm{C}$ and $240^{\circ} \mathrm{C}$ at an extrusion ram speed of $0.1 \mathrm{~mm} / \mathrm{s}$. Billets before the extrusion were $35 \mathrm{~mm}$ in diameter, and the extruded rectangular bars were $3 \times 10 \mathrm{~mm}^{2}$ in cross-section, resulting in an extrusion ratio of 40:1. The as-extruded bars were immediately quenched in cold water. Tensile specimens with a gauge length of $5 \mathrm{~mm}$ were prepared by electric discharge machining. The tensile direction was parallel to the ED. The tensile test was performed in an Instron 5982 machine at the speeds of $0.03 \mathrm{~mm} / \mathrm{min}$ and $0.003 \mathrm{~mm} / \mathrm{min}$, corresponding to initial strain rates of $10^{-4} / \mathrm{s}$ and $10^{-5} / \mathrm{s}$. The microstructure of the as-extruded samples and fracture surface after tensile testing was observed using a FEI Quanta 3D-FEG equipped with a Pegasus Hikari EBSD detector. The as-extruded specimens were prepared by mechanical grinding using $\mathrm{SiC}$ sandpaper, and electro-polishing using a solution of $20 \%$ nitric acid and $80 \%$ methanol, at room temperature and 0.6 Ampere.

\subsection{In-situ synchrotron $X$-ray diffraction}

In-situ synchrotron X-ray diffraction measurements were performed on the powder diffraction (PD) beamline at Australian Synchrotron, ANSTO [37]. Monochromatic X-rays with a beam cross-section of $3 \times 1.2 \mathrm{~mm}^{2}$ and wavelength of $0.5905 \AA$ was incident on the sample. The diffracted X-rays were collected using a Mythen II microstrip detector [38] for rapid acquisition of the high-resolution diffraction data. The diffracted beam signal spanned an angular range of 50.2 $\theta$ and a full pattern was recorded for each loading increment. To improve the grain sampling statistics, the load stage and test piece were rocked 
\pm 17 about the centre of rotation. For each load increment, the diffraction data were recorded over an exposure time of 400 s, coinciding with one full \pm 17 rotation. Instrument calibration was carried out using the National Institute of Standards and Technology standard reference material $660 \mathrm{~b}\left(\mathrm{LaB}_{6}\right)$ powder [39]. The setup of in-situ synchrotron X-ray diffraction was shown in Refs. [40-42].

The tensile deformation was carried out on a $5 \mathrm{kN}$ micro-deformation stage. The tensile test piece was clamped with a pin arrangement for self-aligning the gauge length with respect to the loading axis. A nominal load of $\sim 25 \mathrm{~N}$ was applied to the tensile sample in order to remove any mechanical instability in the sample gripping system. The dimension of the tensile sample gauge volume was $10 \times 3 \times 2 \mathrm{~mm}^{3}$. The loading direction was along the ED and the ND was parallel to the incident beam direction. The thickness of the sample parallel to the incident beam was $2 \mathrm{~mm}$. Tensile loadings were carried out at an extension rate of $0.2 \mathrm{~mm} /$ min, resulting in an initial strain rate of $3.3 \times 10^{-5} / \mathrm{s}$. Samples were loaded in the extension control mode where the samples were loaded until the desired load/stress was achieved. As per the Bragg equation, only grain orientations that had a $\{$ hkil\} perpendicular to (or scattering vector parallel to) the loading direction were measured. During the acquisition of diffraction data, stress relaxation occurred. Then, the value of the strain rate sensitivity was calculated from the stress-time curve, using the equation of $m=d \ln \sigma / d \ln \dot{\sigma}$, where $\sigma$ was the stress, and $\dot{\sigma}$ was the stress rate.

\subsection{In-situ SEM, DIC, and EBSD}

In-situ SEM, DIC and EBSD were performed in a JEOL-7001F equipped with EDAX EBSD detector and a tensile test stage (TSL-TS-1500-II; control system TSL-Tensile Test V6.57). The images were obtained at a constant working distance using an acceleration voltage of $15 \mathrm{kV}$ and a beam current of $12 \mathrm{nA}$, and contains $2500 \times 2000$ pixels. The pixels were used to trace and establish the image correlation with the applied load. The samples for DIC were prepared by mechanical grinding and polishing using OP-S $50 \mathrm{~nm}$-silica suspension. The tensile test stage automatically stopped for every $1 \%$ total elongation for the SEM image acquisition. In-situ EBSD were captured in the as-extruded state, and after $2 \%, 5 \%, 10 \%, 15 \%$ sample elongation. No data cleaning was performed for the EBSD result. The tensile specimen for in-situ SEM and EBSD had a gauge volume of $10 \times 2 \times 1 \mathrm{~mm}^{3}$, and were prepared by electric discharge machining, mechanical grinding, and electro-polishing using a solution of $10 \mathrm{ml}$ perchloric acid and $90 \mathrm{ml}$ ethanol at $-30^{\circ} \mathrm{C}$ at $15 \mathrm{~V}$ for $30 \mathrm{~s}$. The cross-head speed during the in-situ straining was $0.06 \mathrm{~mm} / \mathrm{min}$, corresponding to $10^{-4} / \mathrm{s}$ strain rate. The straining direction was horizontal in the images and maps shown in this paper.

\subsection{In-situ TEM}

In-situ TEM straining experiments were carried out using a Gatan room-temperature straining holder in a JEOL 2010 microscope operated at $200 \mathrm{kV}$. Microstructural evolution was monitored by means of DVD/ HD recording using a MEGAVIEW II CCD camera. Automated crystal orientation mapping (ACOM) was obtained by an ASTAR system operating on a CM20FEG [43]. The corresponding videos, interrupted by ACOM, were recorded on a Gatan Orius camera operated at $15 \mathrm{fps}$. Rectangular micro-samples with size $3 \mathrm{~mm}$ (along the transverse direction, TD) $\times 1 \mathrm{~mm}$ (along the ND) were prepared by electric discharge cutting, followed by mechanical grinding to $50 \mu \mathrm{m}$ thick using 4000 grid $\mathrm{SiC}$ sandpaper. The samples were then ion-polished using Gatan Precision Ion Polishing System (voltage $4.8 \mathrm{kV}$ and angle $4^{\circ}$ ) at $-100{ }^{\circ} \mathrm{C}$ until a small hole formed in the specimen.

\subsection{Data processing}

The data files obtained from EBSD and ACOM were processed using TSL-OIM 8 software. The size of a grain was represented by the equivalent diameter that was calculated from the measured grain area. The in-situ DIC strain analysis was performed using Vic-2D Digital Image Correlation Ver.6.0.6 software. The displacement coordinate maps on the ED-TD plane were produced using the Gaussian weights methods. The in-plane deformation and strain were calculated from the coordinate maps using the Lagrangian finite strain method. The grid spacing for analysis was $0.2 \mu \mathrm{m}$.

For in-situ synchrotron X-ray diffraction analysis, line profile analysis was carried out using TOPAS 5 software (Bruker) [44] to determine pre-

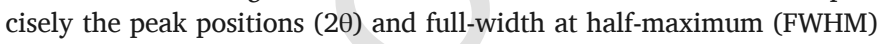
of the in-situ transmission XRD profiles. Single Mg peaks were fit using a Pseudo-Voigt (linear combination of Lorentzian and Gaussian functions) profile fitting function [45]. The background for the entire diffraction pattern was modelled based on a $6^{\text {th }}$ order Chebyshev polynomial. Employing the calibration methodology and the peak fitting procedures described above ensured an absolute value for the peak positions and strain sensitivity of $1.5 \times 10^{-4}$. With $2 \theta$ positions established, interplanar spacings were calculated according to Bragg's law, and the elastic lattice strain was determined using $\varepsilon_{h k i l}=\frac{d_{h k i l}-d_{h k i l}^{0}}{d_{h k i l}^{0}}$, where $d_{h k i l}^{0}$ was the reference (unstressed) lattice plane spacing. From the instrument corrected FWHM results, micro-strain $\varepsilon_{p}$ was calculated following the equation of $\varepsilon_{p}=\frac{\beta}{4 \tan \theta}$, where $\beta$ was peak broadening in radians, and $\theta$ was Bragg angle of the peak. The increment of micro-strain during tensile testing was defined by $\Delta \varepsilon_{p}=\varepsilon_{p}-\varepsilon_{p}^{0}$, where $\varepsilon_{p}^{0}$ was the residue micro-strain in the as-extruded state before tensile testing. The X-ray intensities from grains with $\{10 \overline{1} 0\},(0001),\{10 \overline{1} 1\},\{10 \overline{1} 2\},\{11 \overline{2} 0\},\{10$ $\overline{1} 3\},\{10 \overline{2} 2\},\{20 \overline{2} 3\},\{2 \overline{1} \overline{1} 1\},\{11 \overline{2} 4\},\{2 \overline{1} \overline{1} 3\}$ perpendicular to the tensile direction at each stage of elongation were measured. Based on the intensity measurement, the fractions of such grains were calculated using equation: $\mathrm{I}_{\mathrm{hkl}}=\mathrm{I}_{\mathrm{obs}} /\left(\mathrm{LP}|\mathrm{F}|^{2}\right)$, where $\mathrm{I}_{\mathrm{hkl}}$ is the volume fraction of grains, $\mathrm{I}_{\mathrm{obs}}$ is the measured intensity which was correct for the Lorentz polarisation (LP) and structure factor $|\mathrm{F}|^{2}[40]$.

\section{Results}

\subsection{Microstructure and mechanical properties of as-extruded samples}

The microstructure of the as-extruded samples was characterised using EBSD (Fig. 1). For samples extruded at both $80^{\circ} \mathrm{C}$ and $240{ }^{\circ} \mathrm{C}$, most grains had nearly equiaxed shape. The sample extruded at $80^{\circ} \mathrm{C}$ had fine grains of $1.2 \pm 0.75 \mu \mathrm{m}$ in diameter (denoted FG-Mg hereafter), whereas the sample extruded at $240^{\circ} \mathrm{C}$ (denoted CG-Mg hereafter) had a coarser grain size of $12 \pm 6.2 \mu \mathrm{m}$ in diameter. In the FG-Mg, some unrecrystallised grains were observed, whose area fraction was approximately $10 \%$, and this fraction was decreased to $4 \%$ in the CG-Mg. In terms of texture, both FG-Mg and CG-Mg had a strong [0001] $<10 \overline{1} 0>$ texture, i.e. [0001]//ND and $<10 \overline{1} 0>/ / \mathrm{ED}$. This texture was similar to the rolling texture in the extruded bar. From the EBSD result, it was evident that the only major difference in the microstructure between FG-Mg and CG-Mg was their grain size.

Despite the similar strong basal texture, the FG-Mg and CG-Mg exhibited distinctly different ductility at room temperature. For FG-Mg, subjected to the tensile testing at $10^{-4} / \mathrm{s}$, the elongation was $\sim 100 \%$ (Figs. 2a and b). With a lower strain rate, e.g. $10^{-5} / \mathrm{s}$, the total elongation increased dramatically to $\sim 230 \%$. For the CG-Mg, however, it had much lower ductility, only $\sim 11 \%$, even subject to the same low strain rate of $10^{-5} / \mathrm{s}$. The dash-dot curves show the strain-hardening in Considere-Hart's criterion [46], using equation $\gamma+m=1 . m$ is strain-rate sensitive of $\mathrm{Mg}$ samples, which was measured from stress re- 

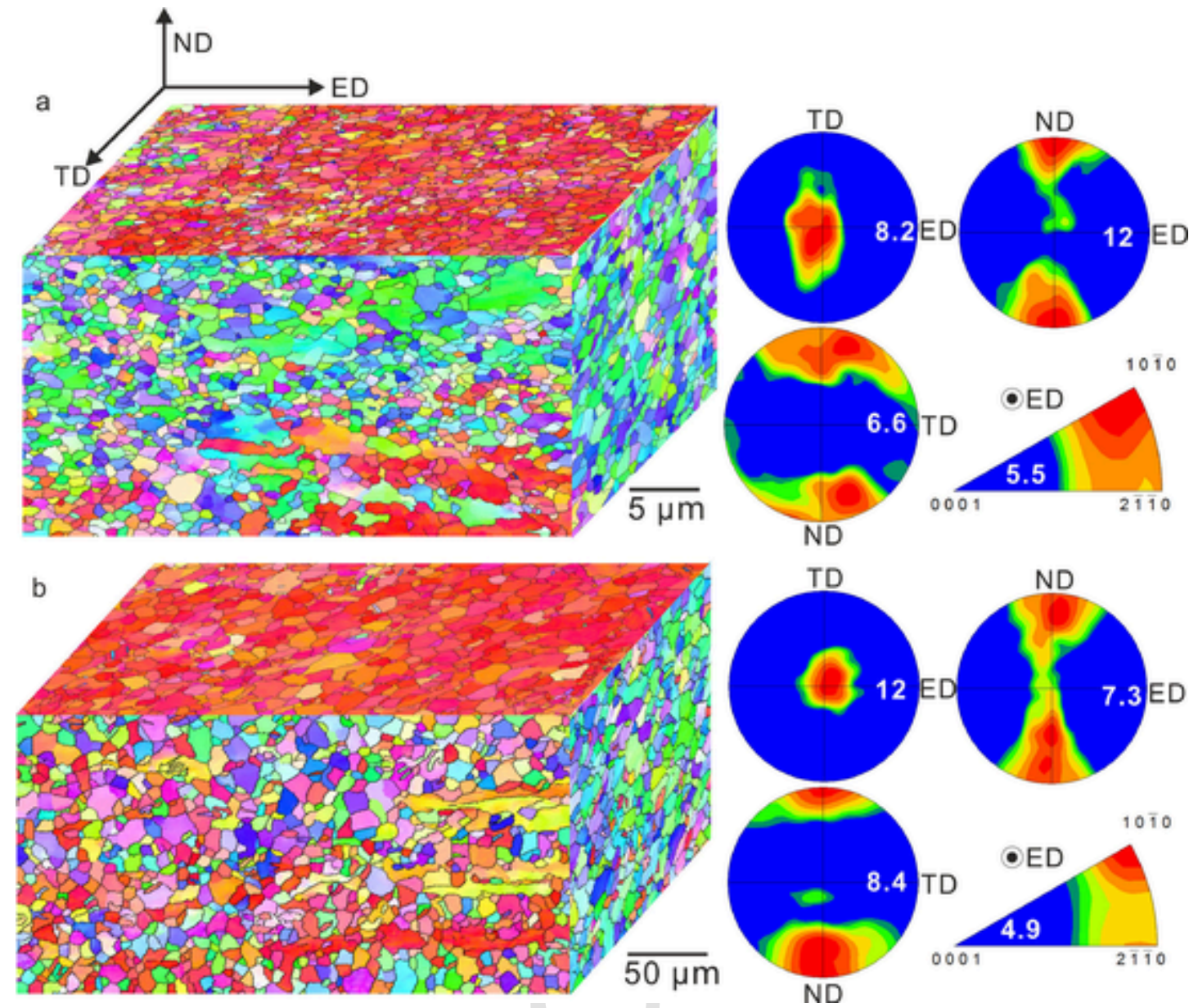

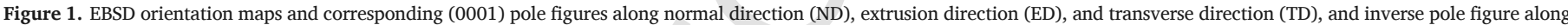
$\mathrm{ED}$, of (a) fine-grained (FG-Mg) and (b) coarse-grained (CG-Mg) samples.

laxation tests (Fig. 3a), whilst $\gamma=d \sigma / \sigma d \varepsilon$ (derived from tensile stress-strain curve). The FG-Mg was found to have a much lower strain hardening than CG-Mg. The intersection points with the stress-strain curves indicated the onset of necking. It was shown that the magnitudes of uniform elongation in FG-Mg and CG-Mg were similar, approximately $8-15 \%$. However, the FG-Mg sample had a very long-range of stable necking, larger than $80 \%$ at $10^{-4} / \mathrm{s}$, and $200 \%$ at $10^{-5} / \mathrm{s}$ strain rates. After tensile testing, the ED-TD surface of samples was observed by SEM. For the FG-Mg after 50\% elongation, numerous fine-grains emerged from the polished surfaces (Fig. 2c). No cracks were observed after such large elongation. As a comparison, after 10\% elongation, the surface of CG-Mg was much smoother (Fig. 2d). The boundaries of some grains were observed, but not as clear as those in the FG-Mg. A major crack was observed along grain boundaries of several grains, which was nearly perpendicular to the tensile direction. It seemed that the grains at the left side of the crack were higher than those at the right side, indicating the relative motion of grains along the ND. The SEM observations further illustrated an evident difference in the fracture surfaces between the FG-Mg and CG-Mg samples. The fracture surface of the FG-Mg sample contained a high density of dimples, indicating a ductile fracture mode (Fig. 2e). In contrast, the fracture surface of the CG-Mg sample was quite flat, which is a signature of brittle fracture (Fig. 2f).

\subsection{In-situ synchrotron $X$-ray diffraction}

In-situ synchrotron X-ray diffraction was utilised to characterise the deformation mode in the bulk material. During measurement, the sample inevitably relaxed during data acquisition (Fig. 3a). Based on the stress relaxation, the calculated values of the strain rate sensitivity were $\sim 0.2$ maximum for FG-Mg and $\sim 0.06$ maximum for CG-Mg (Fig. 3b), which suggested a higher level of inter-granular deformation in the FG-Mg sample. During elongation, the tensile strain led to a shifting of the diffraction peaks towards a lower $2 \theta$ value, whilst the storage of intra-granular dislocations and potential sub-cell formation resulted in diffraction peak broadening [45]. Hence, the examination of the positions and broadening of the diffraction peaks was able to provide insightful information about the deformation mode of samples. Three diffraction peaks with the highest intensity were selected for analysis. They were $\{10 \overline{1} 0\},\{1 \overline{1} 0\}$ and $\{10 \overline{1} 1\}$ peaks as they represented the major proportion of grains in the samples. Figs. $3 c$ and $d$ show the diffraction profile of $\{10 \overline{1} 0\}$ peak of the FG-Mg and CG-Mg, respectively, up to $\sim 8 \%$ elongations. Firstly, it was observed that the peaks in both samples shifted towards lower Bragg angles, which was caused by the increase in lattice plane spacing during the tensile deformation. However, at $8 \%$ elongation, the $\{10 \overline{1} 0\}$ peak of FG-Mg shifted by 0.01 , whilst the peak of CG-Mg shifted by $0.04^{\circ}$. Secondly, the peak broadening in the FG-Mg was much less significant than that in the CG-Mg. Essentially, it was found that, not only the $\{10 \overline{1} 0\}$, but also $\{10 \overline{1} 1\}$ and $\{11 \overline{2} 0\}$ showed increased levels of peak broadening in the CG-Mg than 

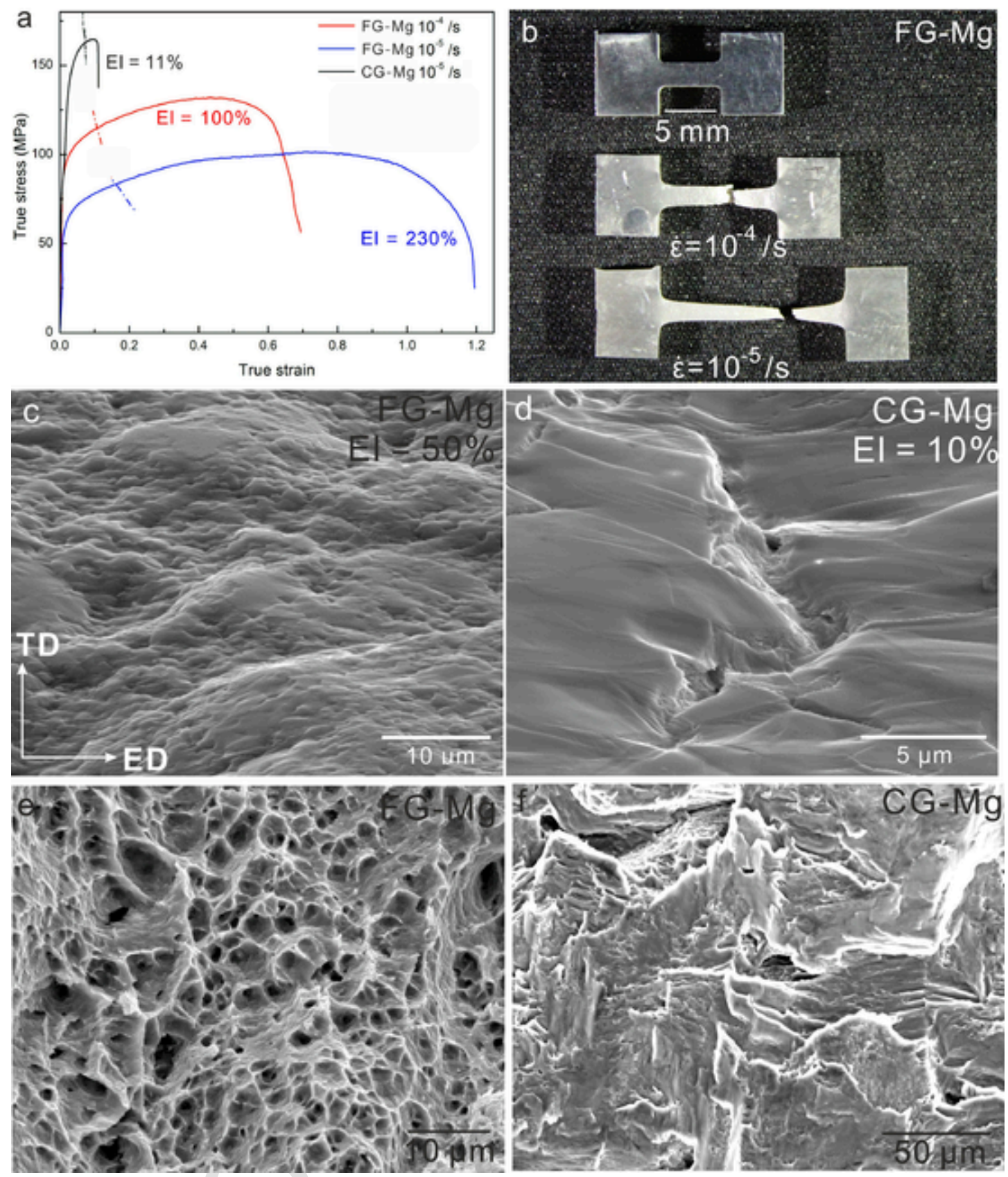

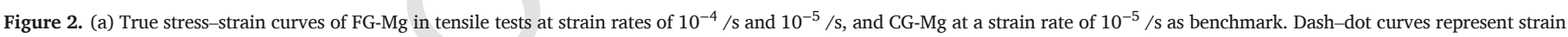

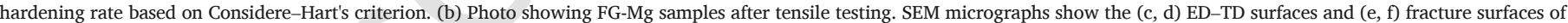
FG-Mg with strain rate of $10^{-4} / \mathrm{s}$ and CG-Mg with strain rate of $10^{-5} / \mathrm{s}$.

in the FG-Mg with the applied load. Therefore, the grain size was found to have a considerable influence on the evolution of lattice plane spacing during the tensile deformation.

In order to quantify the influence of grain size, the measured elastic lattice strain, FWHM, apparent micro-strain, and grain volume fraction, were plotted against the measured percentage gauge length elongation (Fig. 4). Fig. 4a shows the elastic lattice strain $\varepsilon_{h k i l}$ as a function of sample elongation. The elastic lattice strain of the CG-Mg was much higher than that of the FG-Mg. In the CG-Mg, the $\{10 \overline{1} 0\}$ and $\{11$ $20\}$ grains had elastic lattice strain increased in an approximately linear manner up to $3 \times 10^{-3}$, after $8 \%$ elongation. For $\{10 \overline{1} 1\}$ grains in the CG-Mg, elastic lattice strain increased in a similar gradient to $\{10 \overline{1} 0\}$ or $\{11 \overline{2} 0\}$ grains at small elongation, but there was a sharp change in the gradient at $\sim 1.4 \%$ elongation. Beyond this elongation, the increase of elastic lattice strain plateaued with increased elongation. This deflection suggested the relaxation of elastic strain, reportedly caused by the onset of basal dislocation slip [40, 47, 48]. In contrast, in the FG-Mg (Fig. 4a), the evolutions of elastic lattice strain from all the measured peaks were similar - all exhibited much lower gradient in the strain-elongation curves and the overall magnitude of the elastic strain was almost an order of magnitude lower than those in the CG-Mg. Even after the FG-Mg sample was stretched by $55 \%$ elongation, the values of $\{10 \overline{1}$ $0\},\{11 \overline{2} 0\}$ and $\{10 \overline{1} 1\}$ lattice strain were only $6.5 \times 10^{-4}, 6.3 \times 10^{-4}$, and $5.5 \times 10^{-4}$, respectively. During deformation at room temperature, such low values of elastic lattice strain have not been reported before. The results are indicative that the microstructure does not experience significant growth in tensile strain even at high levels of elongation. 

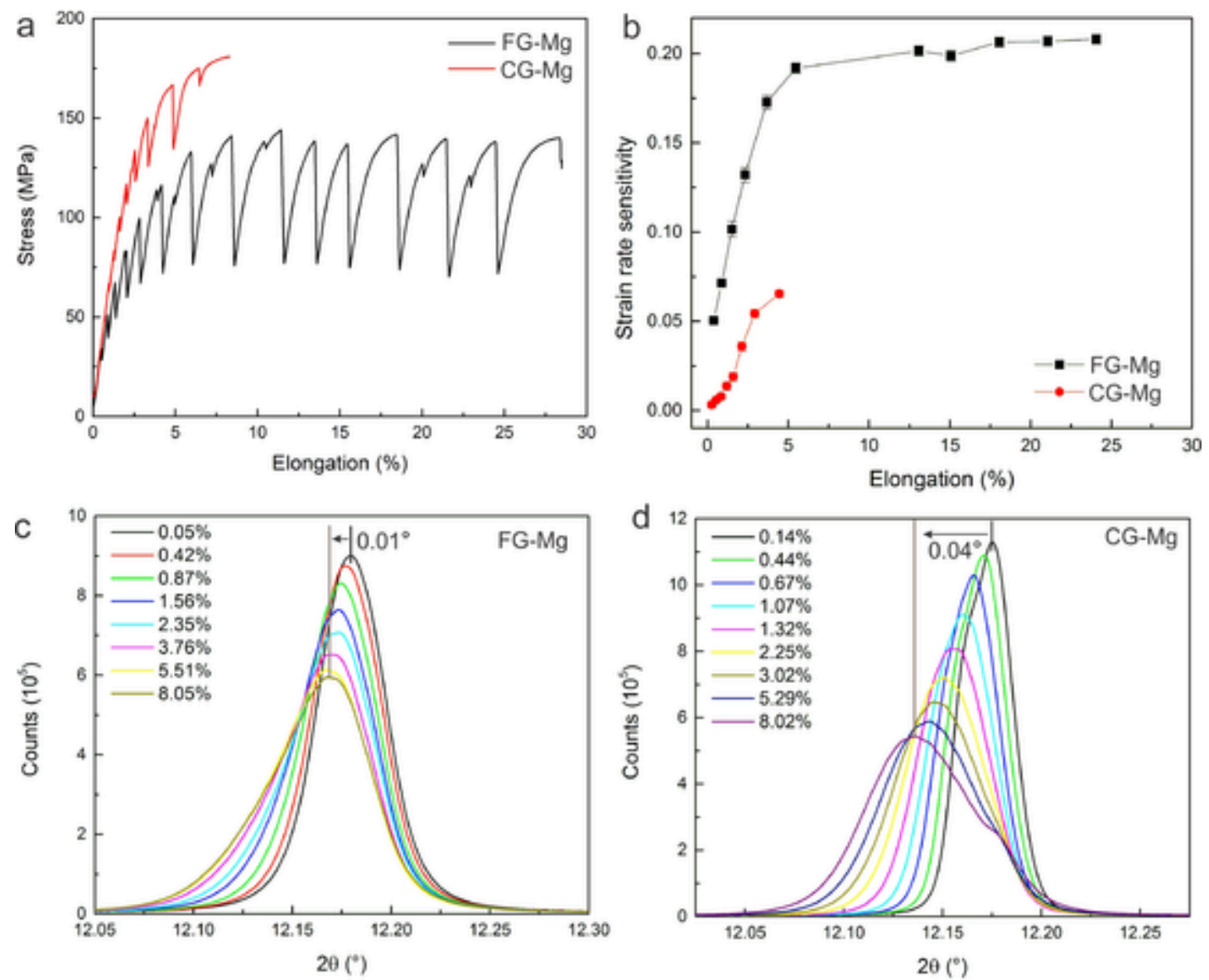

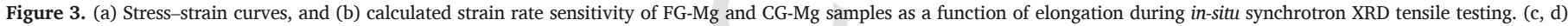
$2 \theta$ scan profile of $\{10 \overline{1} 0\}$ peak of the FG-Mg and CG-Mg respectively up to $\sim 8 \%$ elongation.

Figure 4b shows the FWHM of the diffraction peaks as a function of sample elongation. At nominal load, the anisotropic peak broadening in FWHM data for the FG-Mg sample was higher than the CG-Mg sample, predominantly caused by the distinctly different grain size of $1.2 \mu \mathrm{m}$ and $12 \mu \mathrm{m}$, respectively. Based on the FWHM data, the micro-strain $\varepsilon_{p}$ was calculated. In order to highlight the increment of micro-strain during the tensile testing $\left(\Delta \varepsilon_{p}\right)$, the residual micro-strain in the as-extruded state was $\varepsilon_{p}^{0}$ was deducted from $\varepsilon_{p}$. It was found that $\Delta \varepsilon_{p}$ in the FG-Mg was much lower than that in the CG-Mg in all the peaks (Fig. 4c). For $\{10 \overline{1}$ $0\}$ and $\{11 \overline{2} 0\}$ grains of CG-Mg, the values of $\Delta \varepsilon_{p}$ after $\sim 8 \%$ elongation were approximately $3.7 \times 10^{-3}$ and $4.0 \times 10^{-3}$, respectively. This was $\sim 3$ times higher than those in the FG-Mg at the same elongation. It was noted that in the FG-Mg, the maximum $\Delta \varepsilon_{p}$ occurred when the sample was tensile strained by $\sim 22 \%$. With further elongation, the value of $\Delta \varepsilon_{p}$ plateaued. When the elongation of FG-Mg was increased to $\sim 55 \%$, the value of $\Delta \varepsilon_{p}$ was still only $2.0 \times 10^{-3}$ for $\{10 \overline{1} 0\}$ grains and $1.5 \times 10^{-3}$ for $\{11 \overline{2} 0\}$ grains. For $\{10 \overline{1} 1\}$ grains of FG-Mg, the value of $\Delta \varepsilon_{p}$ was even lower, approximately $1.1 \times 10^{-3}$. In contrast, for the CG-Mg, the maximum values of $\Delta \varepsilon_{p}$ in the $\{10 \overline{1} 1\}$ grains of the CG-Mg was much higher, $\sim 3.0 \times 10^{-3}$, and $\Delta \varepsilon_{p}$ increased steadily with increasing elongation. The observed low level of apparent plastic strain supports the controlled stress concentration in the FG-Mg.

Figure 4d supported the EBSD observation (Fig. 1) that FG-Mg and CG-Mg have similar strong basal texture in the as-extruded state in which $\{10 \overline{1} 0\}$ and $\{11 \overline{2} 0\}$ grains were majority. Specifically, the $\{10$ $\overline{1} 0\}$ grains had the highest fraction, about $41 \%$ in FG-Mg and $36 \%$ in CG-Mg, followed by $\{11 \overline{2} 0\}$ grains (23\% in FC-Mg and $24 \%$ in CG-Mg). Despite similar initial texture, the evolution of $\{10 \overline{1} 0\}$ and $\{1 \overline{1} \overline{2} 0\}$ grain fraction were different in the FG-Mg and CG-Mg during in-situ synchrotron tensile deformation. In the CG-Mg, the volume fraction of $\{10$ $\overline{1} 0\}$ and $\{1 \overline{1} \overline{2} 0\}$ grains slightly increased by $1-2 \%$ with elongation. In contrast, in FG-Mg, volume fraction of $\{10 \overline{1} 0\}$ and $\{11 \overline{2} 0\}$ grains decreased in larger magnitudes from $41 \%$ to $33 \%$ and from $23 \%$ to $20 \%$, respectively. This demonstrates that a greater grain orientation change occurred in FG-Mg during the tensile test; whereby the grains with initially hard orientations (such as $\{10 \overline{1} 0\}$ and $\{11 \overline{2} 0\}$ grains), were rotated away with increased elongation.

\subsection{In-situ SEM observations}

Whilst a rapid increase in strain has been observed in the CG-Mg and other $\mathrm{Mg}$ alloys whose deformation were dominated by intra-granular dislocation slip [38, 39], it is the first time to observe such a low elastic lattice strain in the FG-Mg synchrotron diffraction results even after substantial elongation at room temperature. In order to reveal why FG-Mg has such a unique low strain accumulation, the microstructural evolution of the FG-Mg was monitored at the mesoscale, using the in-situ SEM imaging during tensile deformation. The sample stage was tilted by $20^{\circ}$ around the tensile direction, and thus small differences in surface height could be observed. The in-situ SEM characterisation (Figs. $5 a-f)$ clearly shows the plastic deformation progressed by the relative motion of grain groups, such as those label by I, II, and III. The relative displacement between grain groups I and II led to the formation of a shear band nearly along the TD, whilst the relative motion between grain groups II and III resulted in a zigzag surface step in the FG-Mg (Fig. 5a). With the increase in the tensile elongation, the shear 

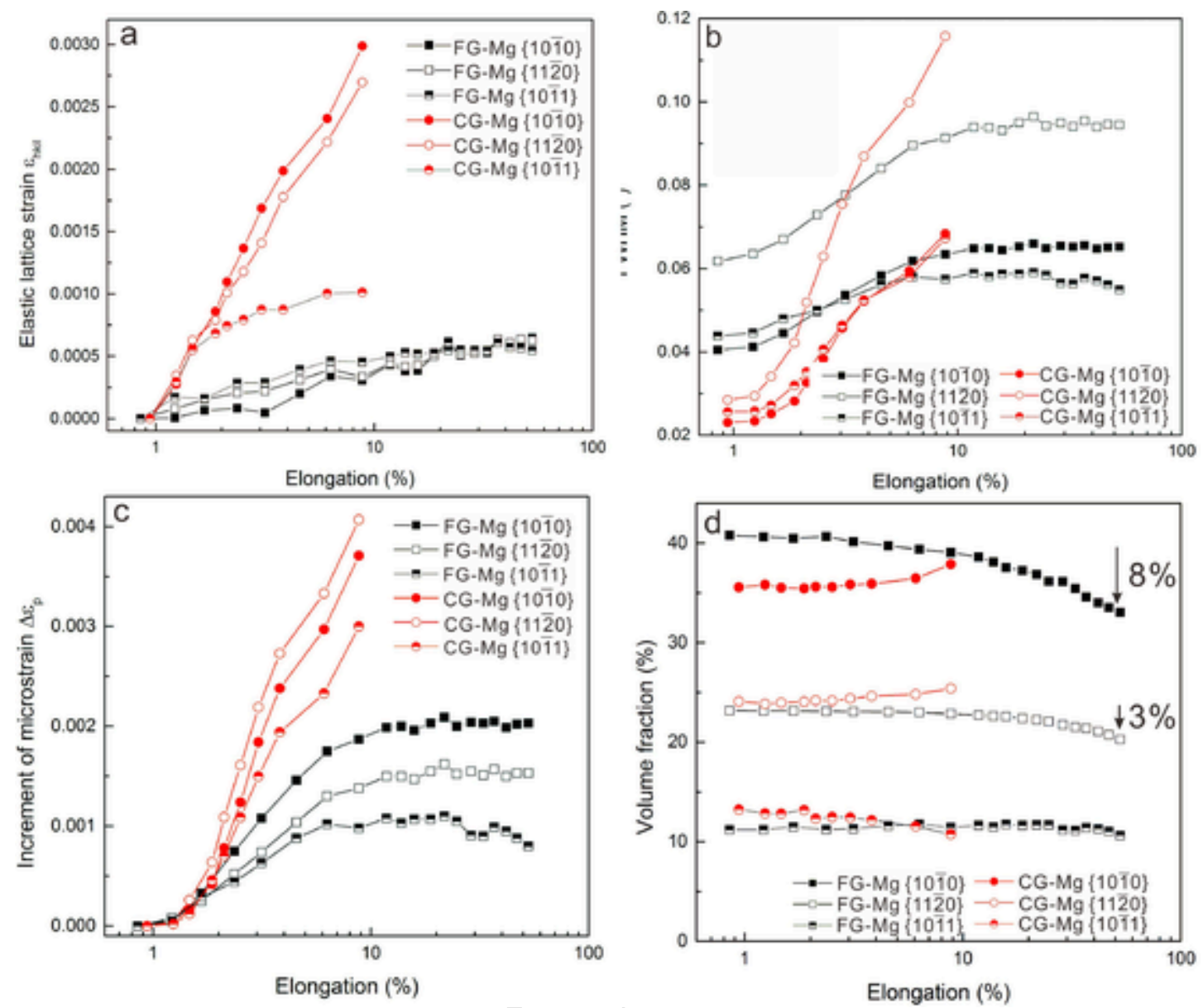

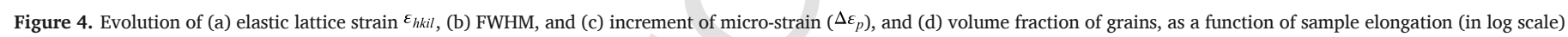
in grains with $\{10 \overline{1} 0\},\{11 \overline{2} 0\}$ or $\{10 \overline{1} 1\}$ normal to the tensile direction.
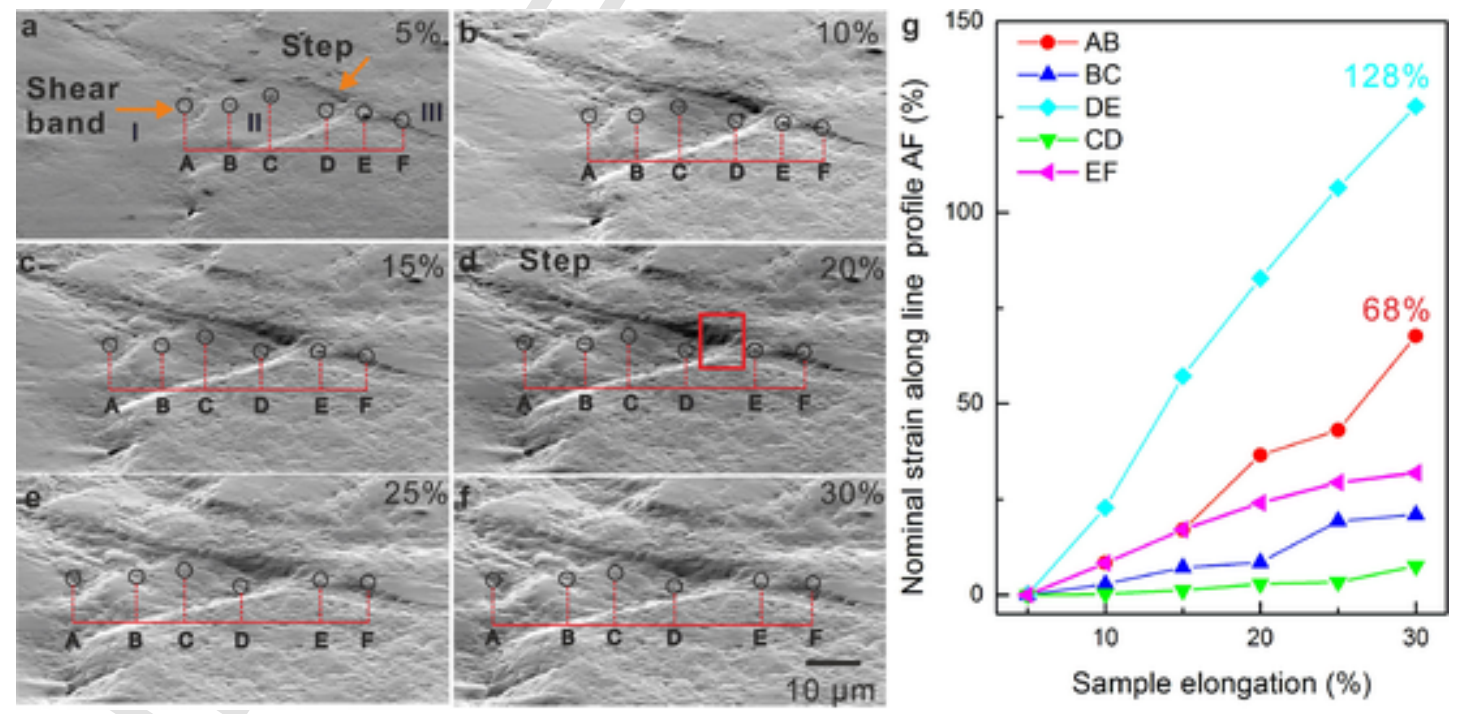

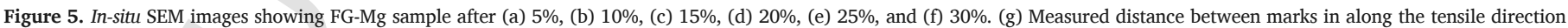
as a function of sample elongation.

band became wider, whereas the step height increased but the slope of the step decreased (Figs. 5b-f).

Surface features, e.g. cavities or protrusions, were selected as the marks for strain estimation. These marks were aligned such that they deform in a manner that is rationalised by the line segment. The dis- tance between marks projected along the tensile direction, $\mathrm{AB}, \mathrm{BC}, \mathrm{CD}$, $\mathrm{DE}$, and EF, were measured during in-situ SEM (Fig. 5g). AB crossed the shear band between grain groups I and II, and DE crossed the step between grain groups II and III. It was observed that the tensile strain of DE was remarkably high, $\sim 128 \%$ when the sample was stretched by 
$30 \%$, followed by tensile strain of $\mathrm{AB}$ of $68 \%$. As a comparison, the strain of segments within each grain groups, such as $\mathrm{BC}, \mathrm{CD}$, and $\mathrm{EF}$, were much lower (less than $30 \%$ ). During the sample elongation from $5 \%$ to $30 \%$, AF was elongated from 40 to $58 \mu \mathrm{m}$, whilst $\mathrm{AB}$ and $\mathrm{DE}$ was elongated from 8 to $13.5 \mu \mathrm{m}$, and from 7 to $16 \mu \mathrm{m}$, respectively. The combined elongation of profile $\mathrm{AB}$ and $\mathrm{DE}$ accounted for $81 \%$ of the total elongation of profile AF. Therefore, the grains in shear band or between steps seemed subject to more severe deformation than those grains within the grain groups. To assess the deformation within shear band, further in-situ SEM at higher magnification, EBSD and DIC was used.

At the corner of the zigzag step (location highlighted in red rectangle in Fig. 5d), two neighbouring grains, labelled A and B, were selected. For Grain A, a step with a height of $\sim 0.06 \mu \mathrm{m}$, caused by GBS, was formed after 5\% elongation (Fig. 6a). During sample elongation from $5 \%$ to $15 \%$, the height of this step increased to $0.06 \mu \mathrm{m}$ and $0.12 \mu \mathrm{m}$, respectively. The further stretching of the sample did not effectively increase the step height by GBS (Figs. 6b-d). Even after the sample was stretched by $25 \%$, the step height was almost unchanged. With respect to the intra-granular deformation of Grain $\mathrm{A}$, the grain diameter showed no increase as the elongation was increased from $5 \%$ to $15 \%$. However, from $15 \%$ to $25 \%$ sample elongation, Grain A was stretched from 1.7 $\mu \mathrm{m}$ to $2.2 \mu \mathrm{m}$ along the tensile direction. The intra-granular strain was then calculated from the elongation of grain $\mathrm{E}$ along the tensile direction, whilst the strain that was caused by GBS (that contributed to sample total strain) was calculated from the grain boundary offset, using the model $\varepsilon_{G B S}=k \frac{v}{L}$ ( $v$ is the displacement in step height, $L$ is the diameter of grain along the tensile direction, $k$ is a coefficient of 1.5). This model was proposed by Bell and Langdon [49]. The operations of GBS and intra-granular deformation led to an elongation of $\sim 30 \%$ for this individual grain.

In grain $\mathrm{B}$, grain rotation and much more significant intra-granular deformation were observed (Fig. 6). As the grain boundary at the right-hand side could not be distinguished, only a part of grain B, which was marked by the grain boundary at the left-hand side and the cavities (Fig. 6b), was observed. Grain rotation started at small sample elongations $(<5 \%)$, and it led to formation of an inclined plane of Grain $\mathrm{B}$ with respect to the reference surface (Fig. 6a). With further stretching, several straight slip lines were readily observed on the inclined plane, suggesting the operation of dislocation slip (Fig. 6b). At a sample elongation of $10 \%$, the length of Grain B along the tensile direc- tion was $0.8 \mu \mathrm{m}$ (Fig. $6 \mathrm{~b}$ ). When the sample was stretched from $10 \%$ to $15 \%$, a step was formed from the inclined plane. The step was $0.5 \mu \mathrm{m}$ in length (Fig. 6c). With the further stretching of the sample to $25 \%$ elongation, another step with a length of $0.8 \mu \mathrm{m}$ was formed from the inclined surface, and now the length of Grain B along the tensile direction was $2.2 \mu \mathrm{m}$ (Fig. 6d). During sample elongation from $10 \%$ to $25 \%$, the inclined plane became a staircase, which led to a dramatic elongation of $163 \%$ of the observed fraction of grain B along the tensile direction.

In order to validate the observation in Fig. 6, the evolution of another grain was observed using in-situ SEM. Fig. 7 showed that the grain, labelled C, was on the slope of a surface step formed during the tensile testing. The grain boundary of grain $\mathrm{C}$ could be readily observed and a yellow line was used to show the grain diagonal. The resolved length of the yellow line along the tensile direction was measured during tensile testing. Similar to grain B, grain C was also subjected to grain rotation and significant intra-granular deformation, which accommodated the formation of the surface step. The elongation of Grain $C$ along the tensile direction was estimated at $\sim 180 \%$ during the tensile process from $5 \%$ to $30 \%$ elongation. Numerous straight slip traces were observed on the surface of grain C, indicating the operation of dislocation slip. Similarly, a grain (labelled D) next to Grain C also demonstrated significant intra-granular deformation, from $0.4 \mu \mathrm{m}$ to $1.7 \mu \mathrm{m}$ along the tensile direction when the sample was elongated from $5 \%$ to $20 \%$. The close examination of grain D showed that the deformation occurred through an intra-granular mode, with a significant elongation of grain shape along the tensile direction. It was also observed that accompanied by significant intra-granular deformation, the cavities, which were formed due to the incompatibility of the relative motion of adjacent grains, were gradually flattened during further stretching. These cavities did not penetrate or transform into cracks.

Figures $8(a, b)$ showed evolution of a grain outside of shear band or step (within a grain group). It can be observed in Fig. 8b that grain boundary offset was formed between a grain (labelled E) and benchmark surface through GBS, and that grain E was gradually elongated with increased sample elongation from $5 \%$ to $30 \%$. Grain rotation was not observed. Using the equation $\varepsilon_{G B S}=k \frac{v}{L}$, it was estimated that the strain caused by GBS increased from 0.045 at $5 \%$ sample elongation to 0.063 at $10 \%$ sample elongation, and stabilised between $0.075-0.08$ beyond $15 \%$ sample elongation (Fig. 8c). From 5\% to 30\% sample elongation, the intra-granular strain of grain $\mathrm{E}$ increased steadily to 0.16 . In

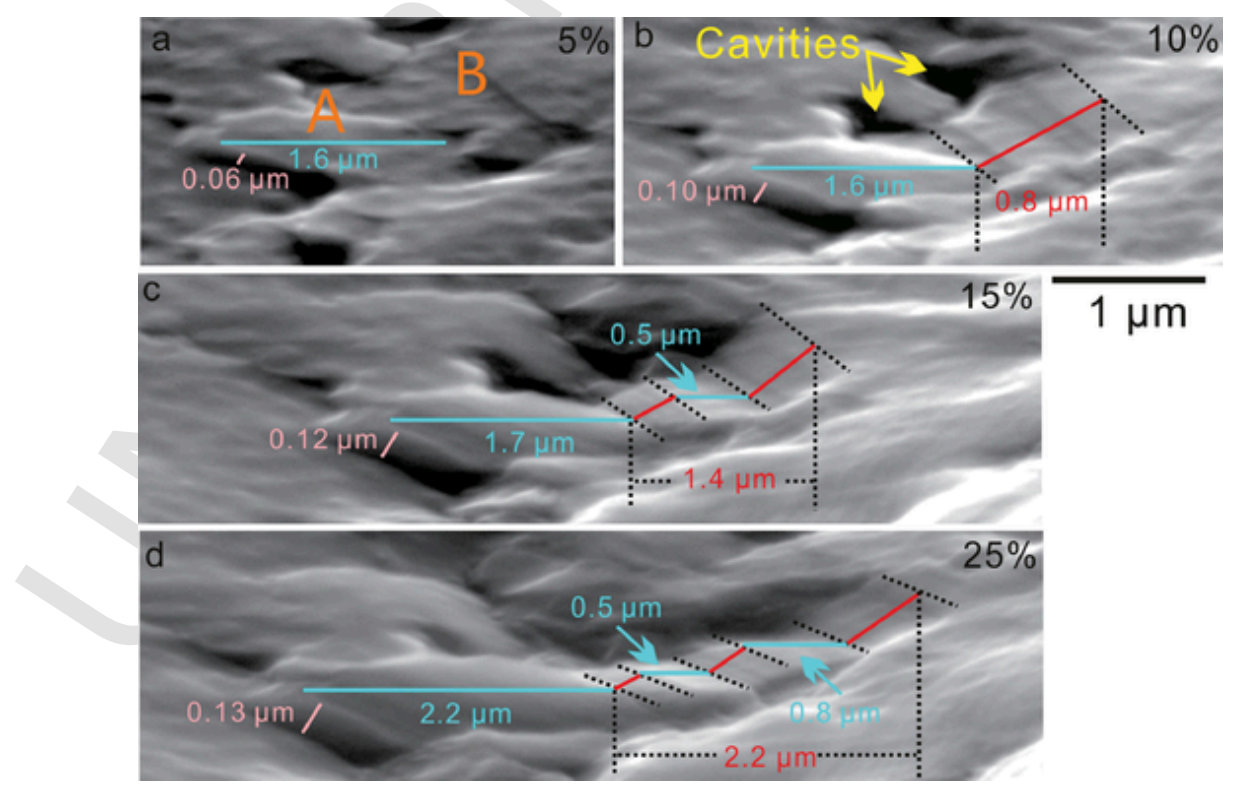

Figure 6. In-situ SEM observation showing the surface morphology of grains A and B subjected to (a) 5\%, (b) 10\%, (c) 15\% and (d) $25 \%$ elongations in FG-Mg sample. 

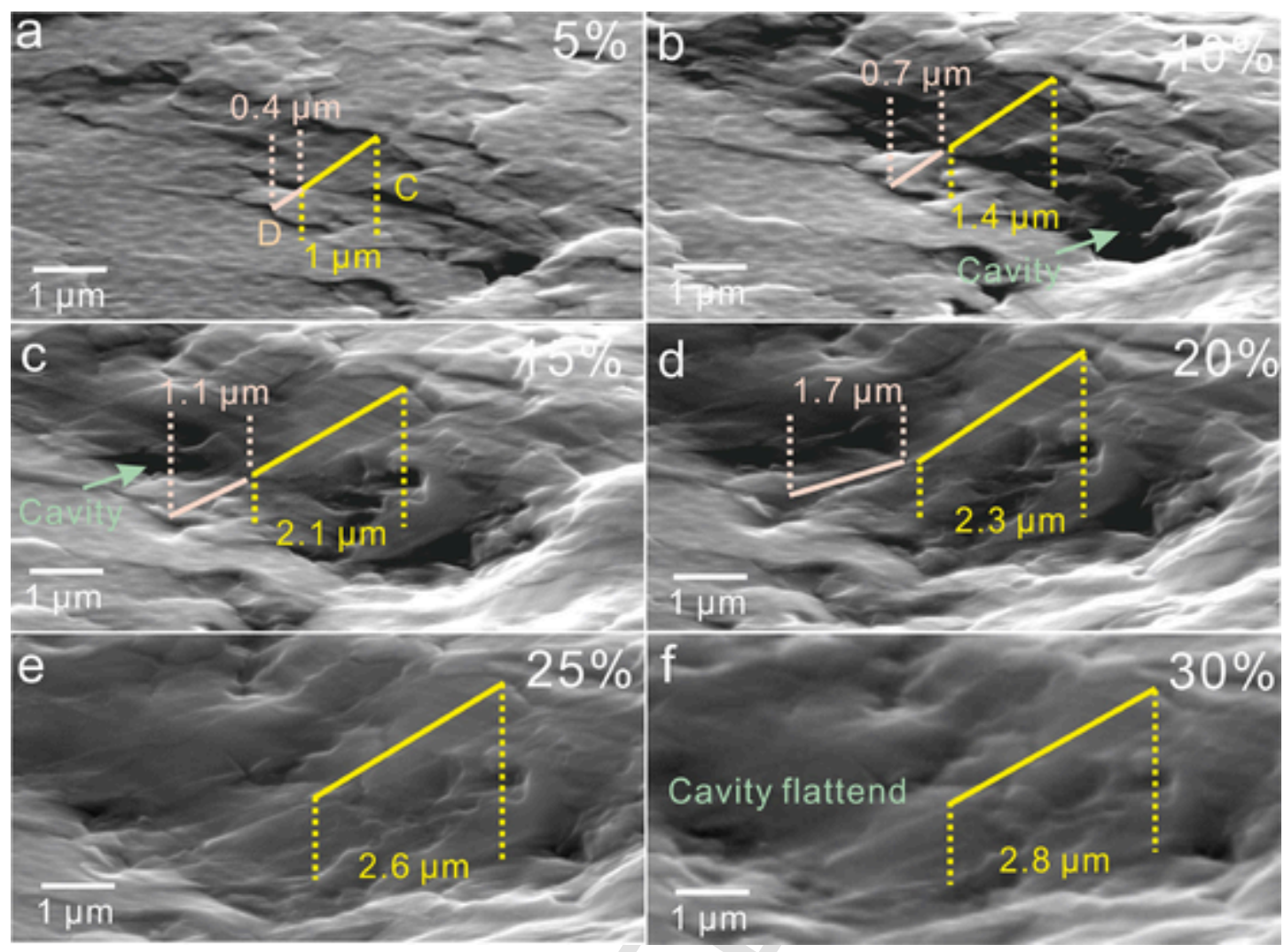

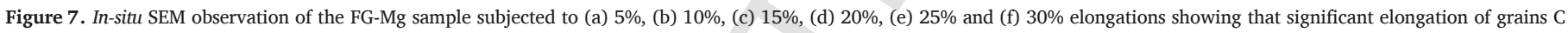
and D. Cavities on the surface after $10 \%$ and $15 \%$ elongations was gradually filled at an elongation of $30 \%$.

the regions outside of shear bands, the local strain contributed by intraand inter-granular deformation in total was less than strain of grain located in shear bands, and also less the sample elongation.

Using the same method, the deformation of 67 grains, including those within and outside of shear band, were examined. The selection criteria of these 67 grains was that their grain boundary offset could be readily observed in SEM image at 5\% sample elongation, allowing the evolution of grain shape to be tracked since early stage of tensile test. The strain caused by intra-granular deformation varied significantly, but strain caused by GBS was similar (Fig. 8d). It was found that although GBS contributed the major fraction of strain at small sample elongations, its contribution to total elongation was decreasing with further elongation (e.g. beyond 15\%). This was because at large elongation, the increase of grain boundary offset was limited, however grains continued to elongate through intra-granular deformation. This observation suggested that GBS between individual grains may contribute to a minor fraction of total elongation in the FG-Mg at $10^{-4} / \mathrm{s}$ strain rate at room temperature.

EBSD was utilised to measure the orientations of grains where shear band or step is formed. Figs. 9a and b show equiaxed grains with strong basal texture in a local region of the FG-Mg sample. In this region, the fraction of grains with strong basal orientations. These grains (grain populations) formed several distinct grain groups as shown in Fig. 9c. Between these strong basal-oriented grains, there were some non-basal oriented grains, which separated the grain groups (Fig. 9d). It was found that a major fraction of these non-basal-oriented grains had high-value Schmid factor for basal slip, indicating the relative ease of operation of basal dislocation slip (Fig. 9e). In contrast, for most of the strong basal-oriented grains, their Schmid factor for basal slip was quite low, suggesting a higher stress required to activate the basal slip in these grains. After 15\% elongation, a shear band (depicted by dark curves) was clearly observed in the SEM image (Fig. 9f). The shape of the shear band was similar to the distribution of non-basal-oriented grains shown in Fig. 9d. This coincidence indicated the presence of soft-oriented grains fostered the formation of shear band during deformation.

In-situ EBSD were used to measure the evolution in grain orientation during the relative motion of grain groups. However, due to the small grain, large local strain, and grain boundary offset, the index rate was too low so that majority of grains could not be tracked using in-situ EBSD. Instead of presenting in-situ EBSD map of whole area, six neighbouring grains (labelled 1-6), which had comparatively higher index rate and could be tracked up to $15 \%$ elongation, were selected for case study. It should be noted that the indexed grain shape might differ from the their real shapes, because the area close to grain boundary might not be indexed, but in-situ EBSD could still measure the orientation of these grain during tensile deformation. The orientation map (Figs. 10a-e) and basal pole figure (Fig. 10f) show the orientation of Grains 1-6. These six grains had diverse orientations. It was noted that Grains 1, 2, 3 , and 5 already had a high-value Schmid factor for basal slip (soft orientations) in the as-extruded state. Grains 4 and 6 had hard orientations $-c$-axis of Grain 4 was only $7 \cdot$ tilted away from the ND, whilst the $c$-axis of Grain 6 was nearly perpendicular to the ND (84०). They both had low values of Schmid factor for basal dislocation slip $(\sim 0.1)$ in the as-extruded state.

It was found that at $5 \%$ sample elongation, the magnitudes of the grain rotation were similar, and relatively small about $3-6^{\circ}$. During elongation from $5 \%$ to $15 \%$, the rotation of Grains 4 and 6 became much more significant than the rest of the selected grains. Up to 15\% elongation, the rotation angle of Grains 4 and 6 were approximately $25^{\circ}$ and $35^{\circ}$, respectively. In contrast, the rotation angle of Grains 1,2 , and 5 was $\sim 15^{\circ}$. For Grain 3 , the rotation angle was $\sim 18^{\circ}$. For Grains 1,2 , 3 , and 5 , the rotation during stretching was not so significant and did not make a big change in their values of Schmid factor for the basal 

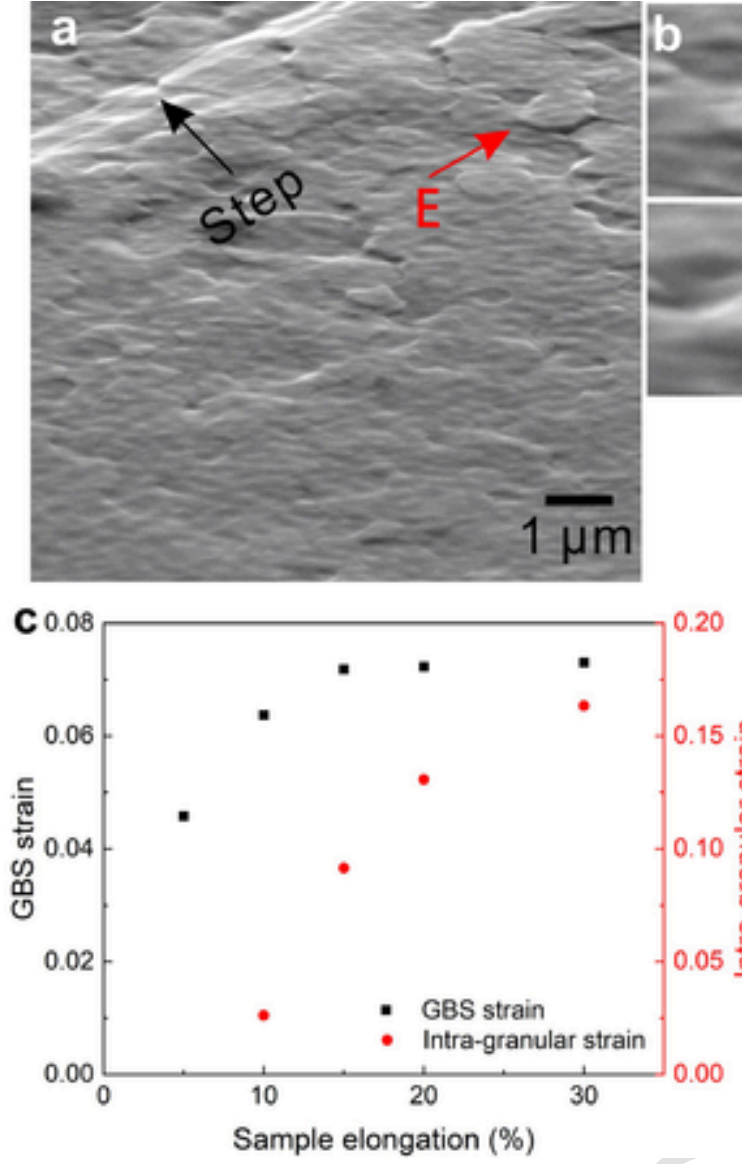
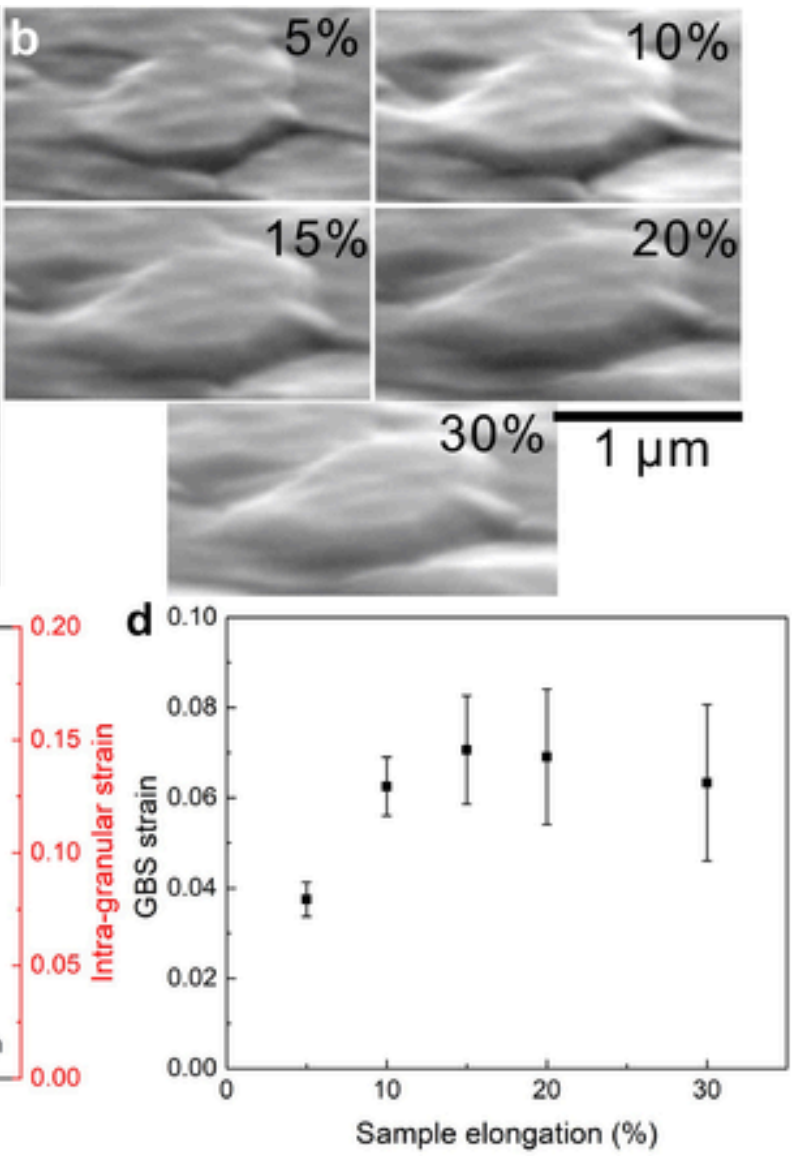

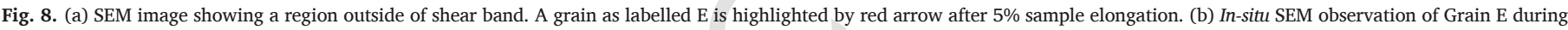

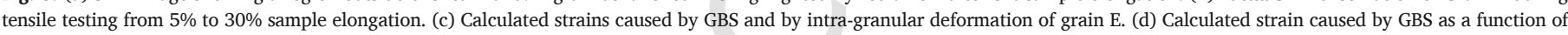
sample elongation from 67 grains in the FG-Mg from 5\% to 30\% elongation based on in-situ SEM observation.

slip (Fig. 10h). In comparison, the rotations of Grains 4 and 6 significantly increased their values of Schmid factor for basal slip to 0.41 and 0.25 , respectively. In shear bands, not all grains had soft orientation initially. It appears that during the formation of a shear band where soft grains were the majority, some grains in this region, which had initially hard orientation, rotated to a softer orientation. Such grain rotation allowed more grains to gain an improved capability of plastic deformation. This observation rationalised the substantial intra-granular deformation of grains B and C, after grain rotation (Figs. 7 and 8), and suggested that such significant intra-granular deformation was most probably to be achieved by the high activity of basal dislocation slip. The operation of basal dislocation slip in fine-grained pure $\mathrm{Mg}$ was also observed and reported by a recent study [50]. The grain rotating away from hard orientation was also supported by the synchrotron X-ray diffraction that showed the decreased fraction of $\{10 \overline{1} 0\}$ and $\{11 \overline{2} 0\}$ with increased sample elongation.

In order to further show the deformation characteristics of FG-Mg at a larger observation area, an indentation matrix was applied to the polished sample surface (Fig. 11a). The indent diagonal was $18 \mu \mathrm{m}$ and the distance between the centre of each unique indent was $85 \mu \mathrm{m}$. Then the sample was tensile deformed up to $50 \%$ elongation, and the deformation of each indent and distance between the centre of neighbouring indents were measured. It was found that at 50\% elongation, the average elongation of the indent diagonal was less than $50 \%$, only $31.6 \pm 13 \%$ along the tensile direction (Fig. 11b). As a comparison, the average elongation between neighbouring indent centre was much larger, at $49.7 \pm 10.3 \%$. We examined the indents whose elongation along the tensile direction more than $50 \%$, and found that they are in- evitably in a shear band (Fig. 11c) or cross a surface step. Given that indent diagonal was shorter than the distance between neighbouring indent centre, each indent was more likely to be within the grain group between shear bands (example shown in Fig. 11d), rather than across a shear band or a surface step. Fig. 11 further demonstrated that deformation was not uniform throughout the sample during testing, and the deformation in shear band or step region was much more significant.

In the next step, the in-situ DIC was used to quantify the strain level and to visualise the in-plane strain distribution (Fig. 12). Shear bands (highlighted by the red arrows in Fig. 12b) was observed after the sample was stretched to an elongation of $10 \%$. With the increase in elongation, the deformation along with the shear bands was more significant than the rest of the sample, and the intersection point of the shear bands was deformed most severely (Figs. 12a-d). A white arrow was drawn across an intersection point in Fig. 12d, and the magnitude of the true strain along this arrow was plotted in Fig. 12e. At the intersection point (highlighted by the green spot in Fig. 9d), the tensile strain increased nearly linearly as a function of elongation, reaching a surprisingly high value of 4.3 (Fig. 12f). However, within the grain groups, the local plastic strain increased at a much slower rate. As highlighted by the yellow spot in Fig. 12d, the strain value of this spot was still quite low, only $\sim 0.27$ even after $50 \%$ elongation. During the whole deformation process, global certainty of the DIC analysis was kept over $98 \%$ and reached close to $100 \%$ at the end of deformation (see supplementary figure 1). 

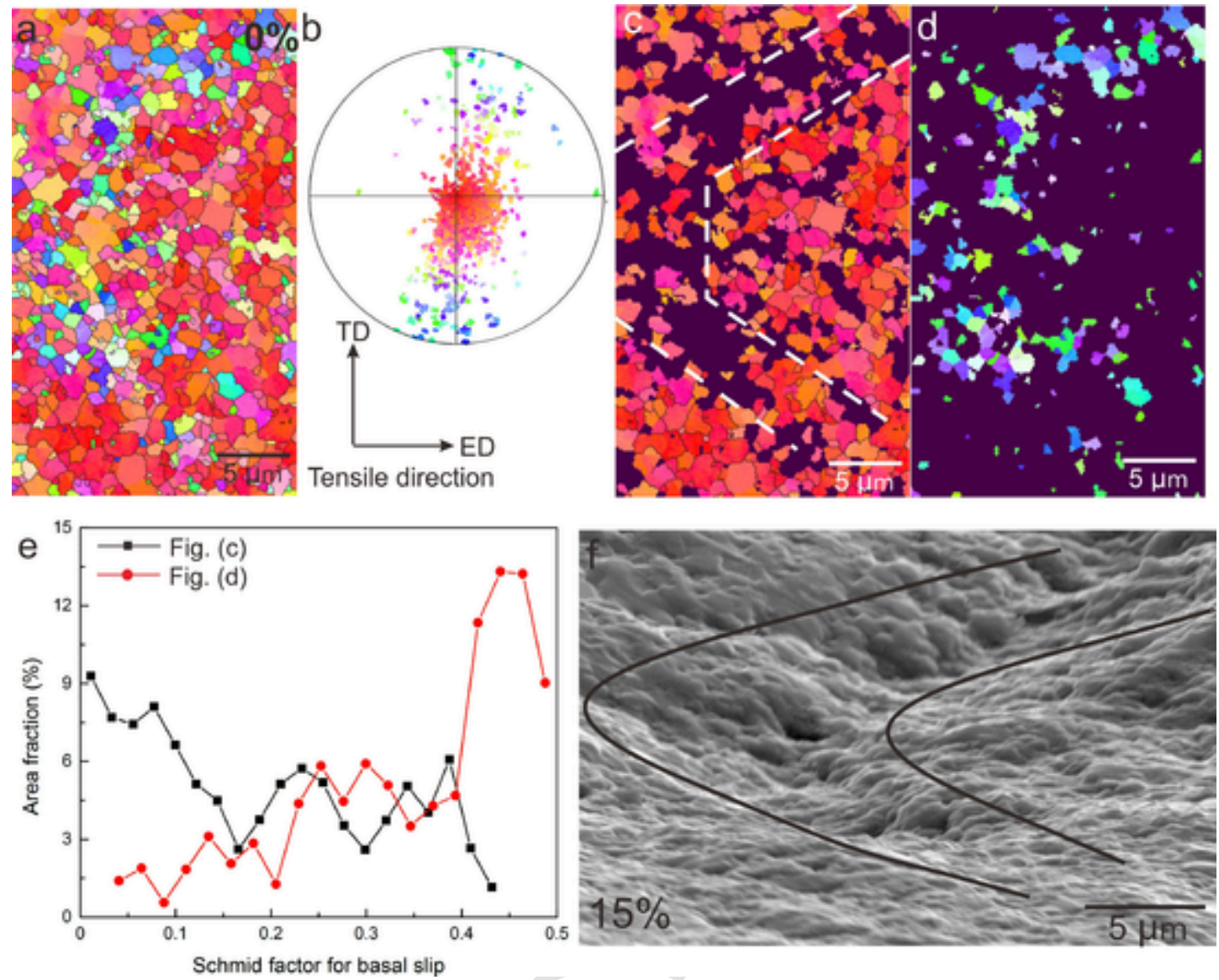

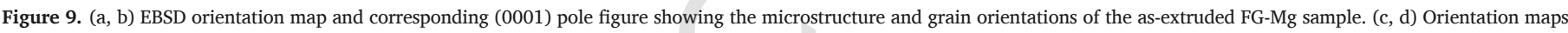

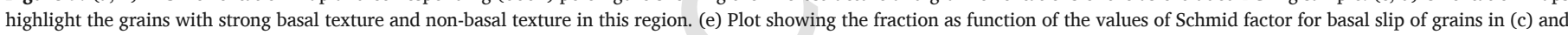
(d). (f) SEM secondary electron image showing a shear band after $15 \%$ elongation (sample tilted by $70^{\circ}$ ).

\subsection{In-situ TEM straining}

The SEM observation of large strain by intra-granular deformation in some grains is further supported by in-situ TEM straining. Fig. 13 (Supplementary video 1 ) showed that in the thin-foil sample, the fine-grains were subjected to significant necking before trans-granular fracture initiated. This phenomenon was not widely observed in $\mathrm{Mg}$, but it was observed in fine-grained thin films of $\mathrm{Al}$ that also present large elongation [51]. The high intra-granular ductility and trans-granular fracture lead to the formation of dimples, which were observed in the SEM image of fracture surface (Fig. 2e).

In the loading experiments, most of the time the dislocation contrast vanished at the grain boundary (Supplementary videos 2 and 3), indicating a rapid decomposition as previously observed in Ref. [51]. Figs. 14a-c (snapshot of Supplementary video 2) showed an example of dislocation-grain boundary interaction. At $t=0$ s (Fig. 14a), a curved dislocation highlighted with a red dashed line, was moving toward the upper grain boundary due to the applied stress. At $t=3.6 \mathrm{~s}$ (Fig. 14b), the dislocation expanded and entered the grain boundary which led to two dislocation segments. The dislocation contrast vanished except at the intersection between the right segment of the dislocation and the grain boundary (indicated by a black arrow). This dislocation eventually remained pinned by the grain boundary. At $t=3.7 \mathrm{~s}$ (Fig. 14c), the left dislocation segment continued to move on the left toward the triple junction without leaving any visible contrast in the grain boundary. This observation clearly indicated that the dislocation has been fully incorporated in the grain boundary. As the grain boundaries seemed to be able to actively absorb of dislocations, deformation was thought to be efficiently transferred along them by GBS, and prevented a strong localisation of deformation in the grain [52]. With respect to grain boundaries, they were quite sessile throughout the entire in-situ TEM straining.

The close examination using in-situ TEM straining in combination with ASTAR-ACOM revealed the important role of grain boundary on ductility. Subjected to large sample elongation, a pre-existing crack propagated nearly perpendicular to the tensile direction. Fig. 15a shows that a crack was approaching a triple junction of grains labelled 1, 2 and 3. When the crack was far from the triple junction, e.g. more than 0.5 $\mu \mathrm{m}$, it propagated at a nearly constant rate, and the sample in front of the crack tip was thinned by intra-granular plastic deformation. When the crack was near the triple junction, the propagation rate decreased (Fig. 15b). The in-situ TEM characterisation (Supplementary video 4 and the snapshots shown in Figs. 15c-f) indicated that the localised thinning zone ahead of the crack tip became diffuse and the crack tip was blunt at the triple junction, which is most probably to be achieved by enhanced ductility near the grain boundary through active emission and absorption of dislocations. It was noted that crack tips and a large variety of GBs with different planes would modify the stress state, which was not a pure tension stress. Herein, we merely made use of large plastic deformation ahead of a crack tip to exam if GB would move under stress. If so, GB migration would be captured as shown in previous studies $[51,52]$. When GBs were on the free surface of TEM foil and subjected to stress concentration in front of crack tip, GB migration should be much easier than that within bulk sample. However, even under this circumstance, the GB migration was still not observed. 

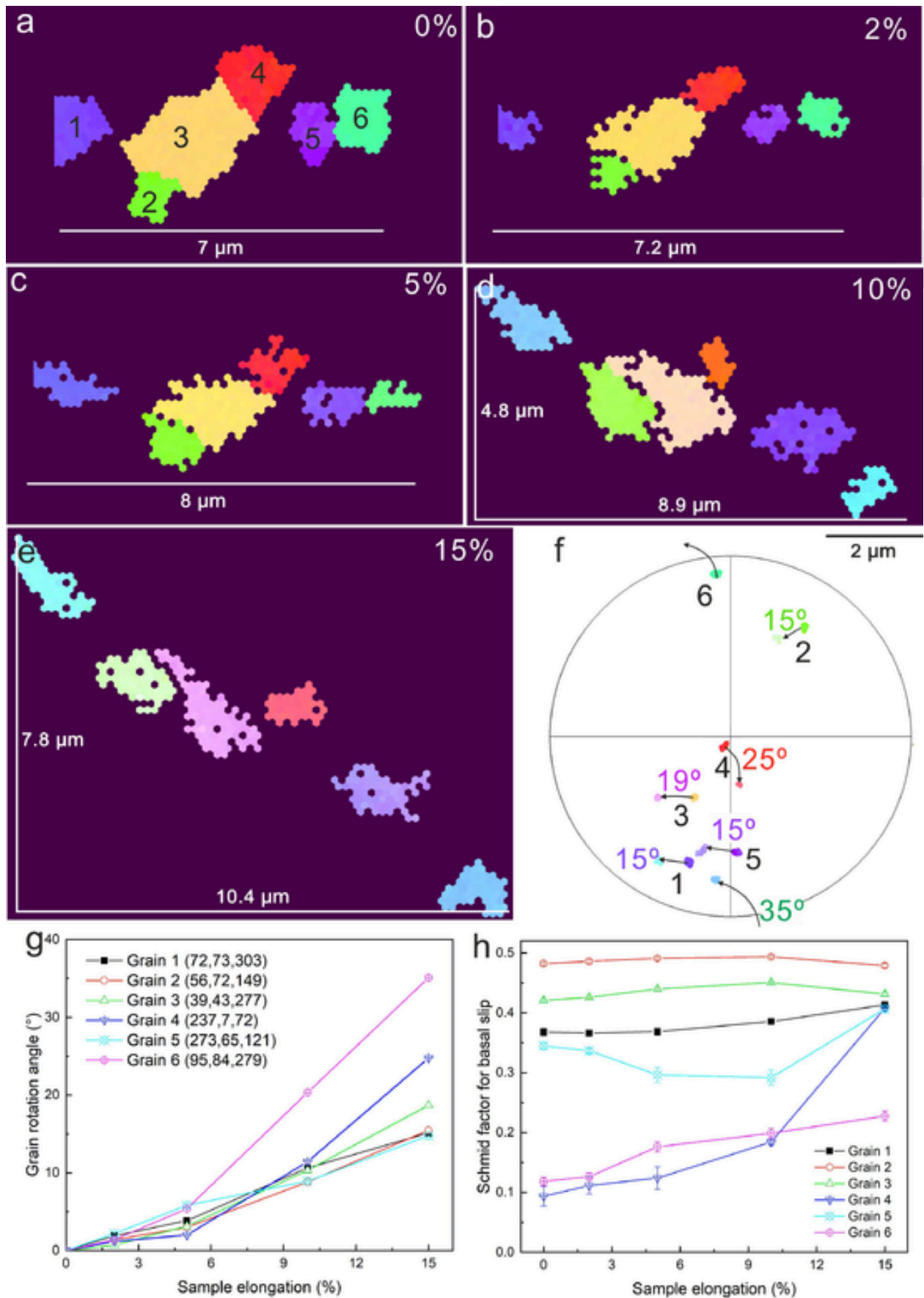

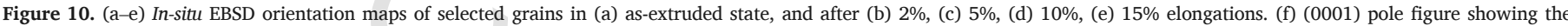

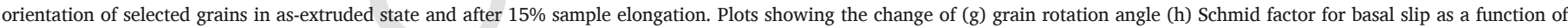
sample elongation in the selected grains. The Euler angle of each grain in the as-extruded state is provided in degrees.

Instead, it was frequently observed that many slip traces cross individual grains from side to side. In such grains, no evidence of GB migration were recorded (supplementary video 5). These in-situ TEM results, which recorded intra-granular rather than inter-granular deformation in different grains, suggested the GBs were immobile, and their migration was even less likely to operate in the bulk sample.

\section{Discussion}

\subsection{Inter-granular deformation mode}

In this study, fine-grained pure $\mathrm{Mg}(\sim 1.2 \mu \mathrm{m}$ in diameter) was uniaxially elongated by $\sim 100 \%$ (at $10^{-4} / \mathrm{s}$ ) and $>200 \%$ (at $10^{-5} / \mathrm{s}$ ) at room temperature despite a strong basal texture. Based on the tensile stress-strain curves, the ductile deformation of FG-Mg at room temperature still exhibits some differences to the superplastic deformation of $\mathrm{Mg}$ alloys at elevated temperature [53-57]. First, the FG-Mg at room temperature has a total elongation of $100-200 \%$, whilst elongation in superplastic deformation is normally more than $400 \%$ [53-57]. Secondly, the flow stress during superplastic deformation is extremely low, normally less than $20 \mathrm{MPa}$, and with negligible work hardening [53-57]. In comparison, the flow stress of the ductile pure $\mathrm{Mg}$ at room temperature is much higher in the range of $50-120 \mathrm{MPa}$, and the work hardening, although low, was still observed. Such differences revealed 

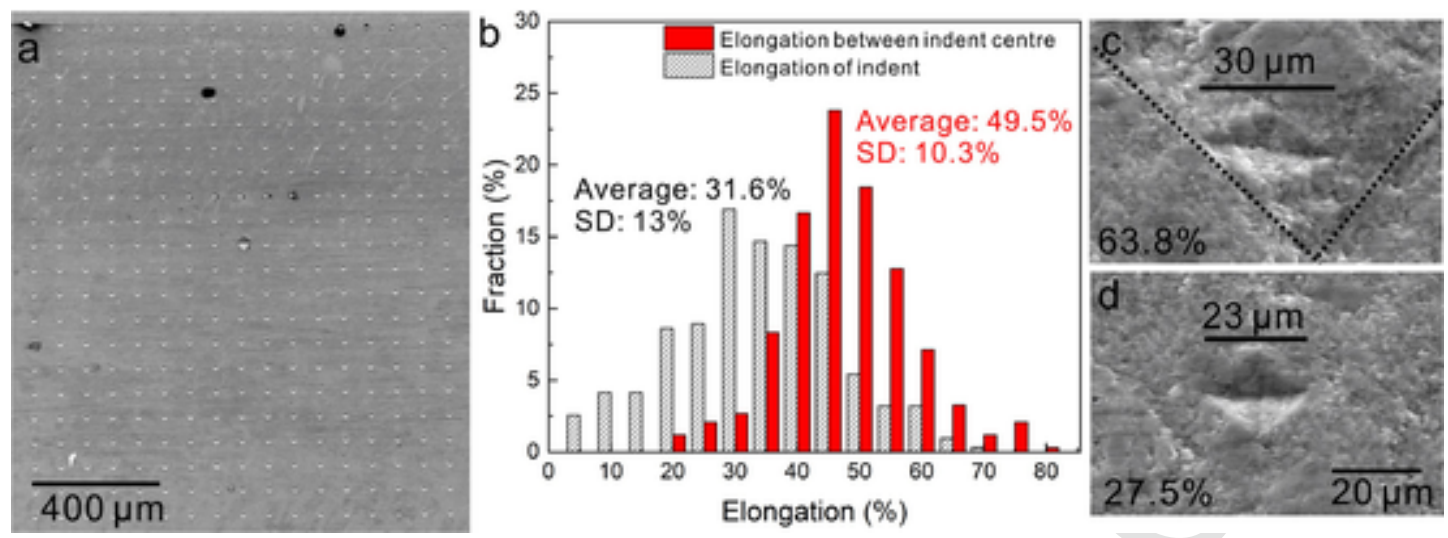

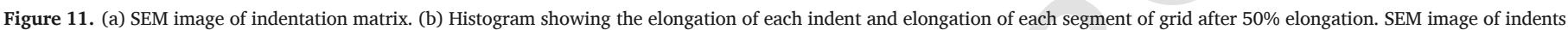
with elongation (c) larger and (d) smaller than 50\%, after 50\% sample elongation.
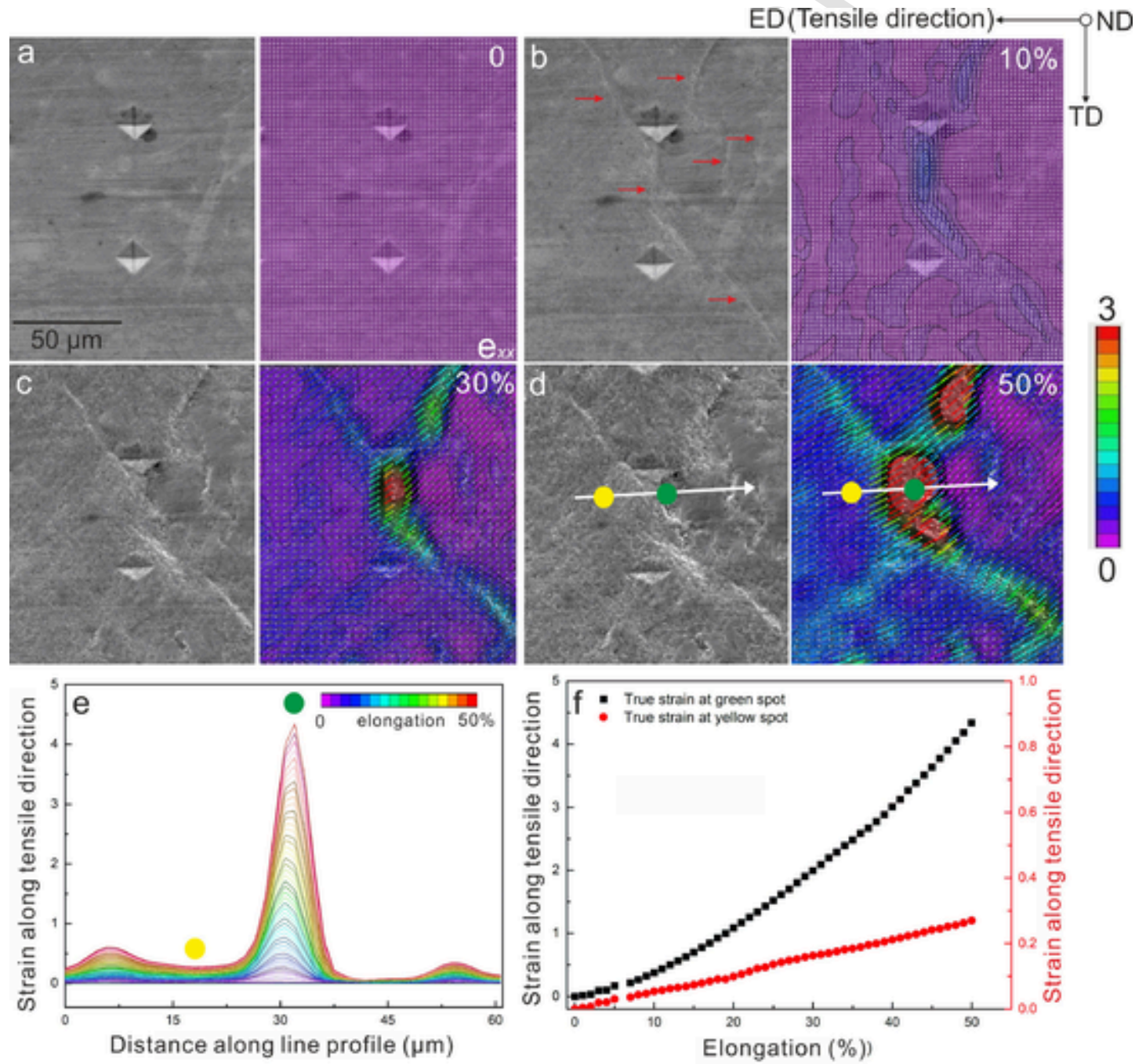

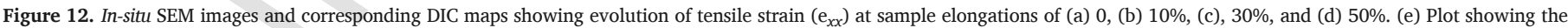

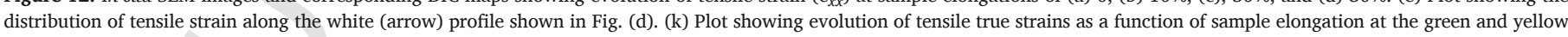
spots in Fig. (d).

by tensile testing may indicate a different deformation mode for high ductility at room temperature, in contrast to the superplastic flow at elevated temperature. In the following sections, we analyze the results from the complementary in-situ diffraction and imaging techniques, and identify the key factor for the extraordinarily high ductility of FG-Mg at room temperature.

First of all, it is necessary to validate whether inter-granular deformation is the dominant mode in the FG-Mg at room temperature. Indeed, how to demonstrate the operation of inter-granular deformation 

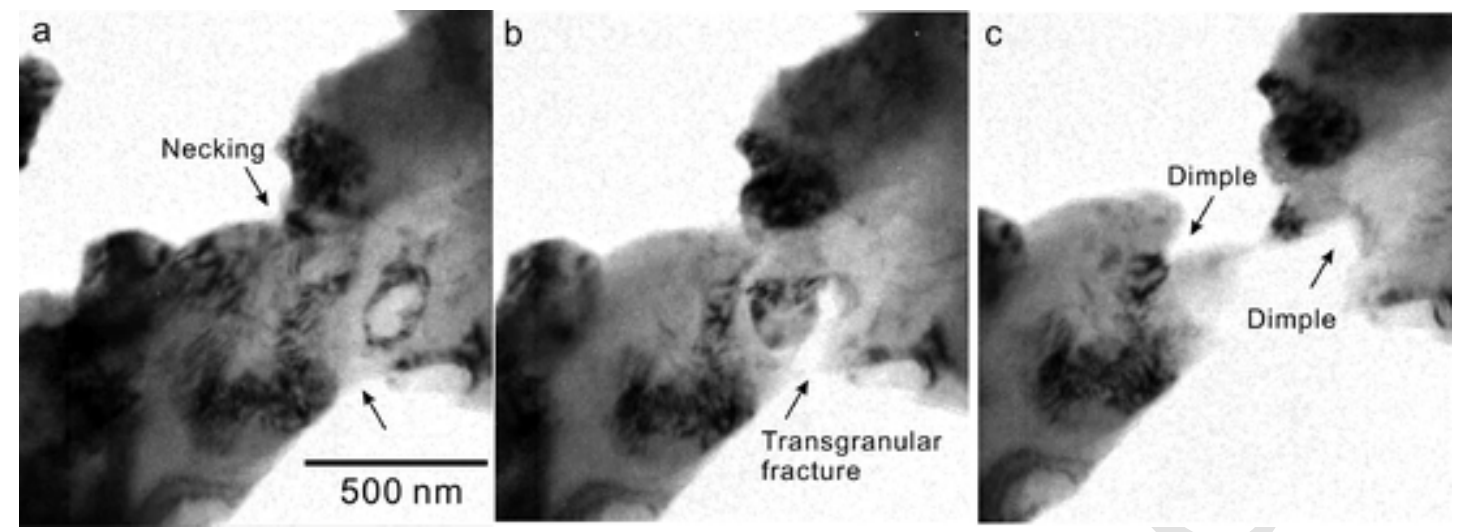

Fig. 13. In-situ TEM images showing the formation of dimple and ductile trans-granular fracture.
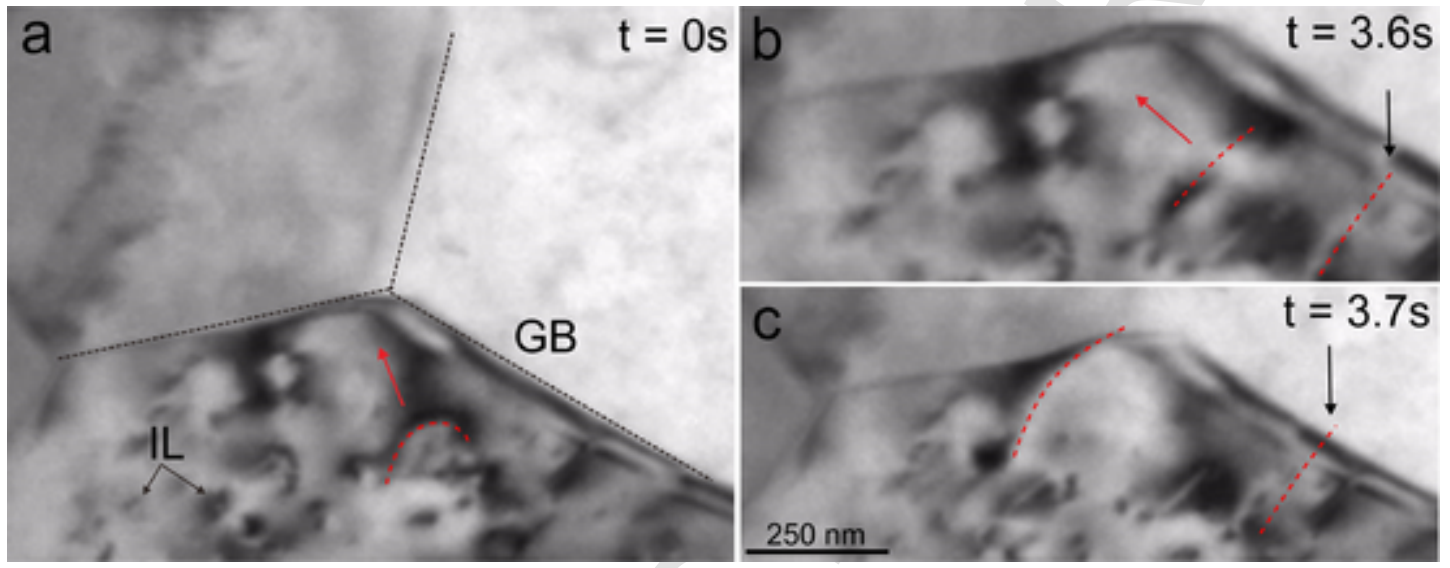

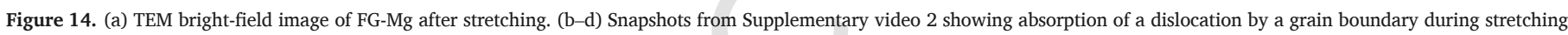
of FG-Mg sample. Irradiation loops (IL) due to electron irradiation can be observed and dislocation lines are highlight by red dashed curves.

within a bulk sample has been a puzzle for a long time. This is because, using SEM or TEM, the observation area is always on the free surface rather inside the bulk sample. Moreover, on the free surface, there is less restriction from the neighbouring grains, and thus grains have higher freedom to be deformed by the inter-granular mechanisms. Even though steps along grain boundaries are formed on the polished surface, it is still difficult to fully prove that the GBS is also operating in the bulk. Another evidence that is widely used to prove the operation of inter-granular deformation is high strain rate sensitivity, which is usually measured by strain-jumping or stress-relaxation tests. If inter-granular deformation such as GBS is the dominant mode, then the $m$-value is $\sim 0.5$. For $m$-value of $\sim 0.2$, it is valid to claim that the operation of inter-granular mechanism is enhanced compared to intra-granular deformation $(m<$ $0.05)$, but it is still difficult to identify whether inter-granular deformation is dominant.

Herein, the transmission in-situ synchrotron X-ray diffraction provides evidence to speculate inter-granular mechanism as the major deformation mode of the bulk sample at the macroscopic scale. For the dominant proportion of grains in the FG-Mg (i.e. the $\{10 \overline{1} 0\},\{1 \overline{1} \overline{2} 0\}$ and $\{10 \overline{1} 1\}$ grains), the elastic lattice strain and FWHM quickly form a plateau and the absolute value of this plateau data is 3-10 times lower than those in the CG sample during tensile deformation (Fig. 4). These results strongly indicate the absence of significant strain accumulation inside these grains in the FG-Mg even at the very high levels of elongation applied. Therefore, the deformation in the FG-Mg must occur predominantly in an inter-granular mode between the grains, but such inter-granular deformation is difficult to assess using the applied bulk synchrotron XRD test.
To account for the plausible inter-granular deformation mode, we examined if the ductile deformation at room temperature was achieved by homogeneous GBS between individual grains. In order to achieve homogeneous GBS as schematically shown in Figs 16a-c, the mobile grain boundaries are required so that they can rearrange themselves during superplastic deformation [58-60]. Otherwise, the incompatibility during GBS will cause a high density of cavities and result in an early fracture. That is why in-situ TEM was used to examine grain boundary mobility in the FG-Mg in this study. The result, however, shows that the grain boundaries are immobile at room temperature, even in front of a crack tip. Hence, it is difficult to rationalise how homogeneous GBS actively operate without mobile grain boundaries. Further evidence against homogeneous GBS is the contribution of the GBS between individual grains to total elongation is quite limited. The magnitude is even less than that of intra-granular strain at large sample elongation. This has been systematically demonstrated by in-situ SEM observations and statistics as shown in Figs. 6 and 8. Then, what is the deformation mode that contributed to the rest (also the major fraction) of total elongation?

Using the in-situ SEM-based-techniques, the inter-granular deformation is observed to occur by relative sliding between grouped grains predominantly with strong basal texture, rather than GBS between individual grains that was observed at elevated temperatures and reported in Refs [53-57]. The local strain caused by the sliding between grouped grains is substantial, e.g. more than 1.0 true strain; there are high density of grouped grains, as demonstrated by numerous surface steps and shear bands between slid grouped grains. Therefore, the active operation of sliding between grouped grains is capable of contributing to considerable strain during tensile testing. Based on the 

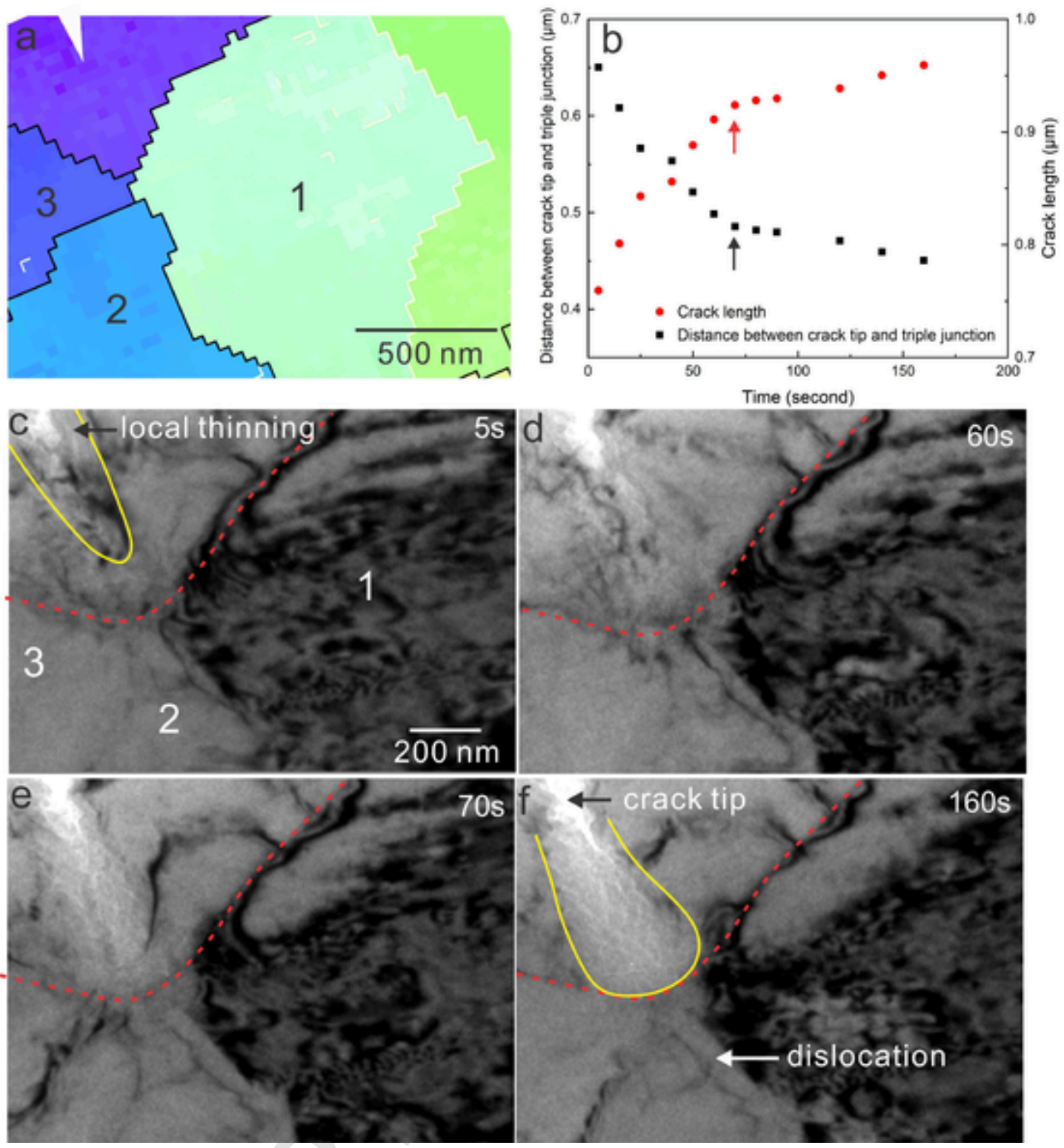

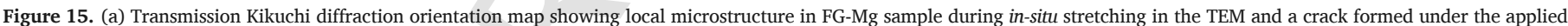

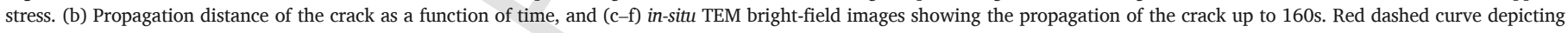
grain boundaries, and yellow curve depicting local thinned region ahead of crack tip.

measurement shown in Fig. 5, the strain caused by the sliding between grouped grains accounts for $\sim 81 \%$ of the total strain, which evidently proves that the major fraction of elongation is contributed by sliding between grouped grains. This long-range cooperation in the process of sliding between groups of grains was reported in previous studies, and was termed as cooperative grain boundary sliding (cGBS) [61-63]. In fine-grained $\mathrm{Cu}$ [64], $\mathrm{Ni}$ [64], $\mathrm{Al}$ [65] and $\mathrm{Pb}$ [66], cGBS was also observed during deformation at room temperature.

It is now established that when the grain size is reduced from $12 \mu \mathrm{m}$ to $1.2 \mu \mathrm{m}$, the dominant deformation mechanism transitions from dislocation slip to a $c$ GBS, rather than homogeneous GBS between individual grains. To illustrate, a schematic figure of $c \mathrm{GBS}$ is shown in Figs. $16 \mathrm{~d}-\mathrm{i}$. The sample starts to be deformed by sliding between grouped grains even at small strains. The groups of grains are those with similar strong basal orientation. The strong basal orientation makes them difficult to be deformed either by intra-granular or inter-granular mechanisms. However, between them, there are grains with softer orientations, allowing the initiation of $c$ GBS (Fig. 16d). For $c$ GBS, a common plane is required to allow the grain groups to slide; the model is demonstrated in Ref. [61]. The formation of the common plane can either be achieved by the alignment of existing grain boundaries under load or by forming a band by intra-granular slip crossing a grain [61]. Given that the grain boundary is immobile in FG-Mg, the formation of a band can only be achieved by intra-granular slip. This is why cGBS tends to initiate in the grains with soft orientations (as observed in Fig. 9).

\subsection{Accommodation mode of cGBS}

While the $c$ GBS has been demonstrated in this study to be the major deformation mode, there is still a critical question about cGBS: what is the accommodation mechanism for the sliding between grouped grains? In both FG-Mg and CG-Mg, grains tend to slide against each other, but only the grain sliding in FG-Mg is accommodated, whilst the grain sliding in CG-Mg results in tearing at the grain boundaries (as shown in Fig. 2d). Therefore, the effective accommodation of the slid- 

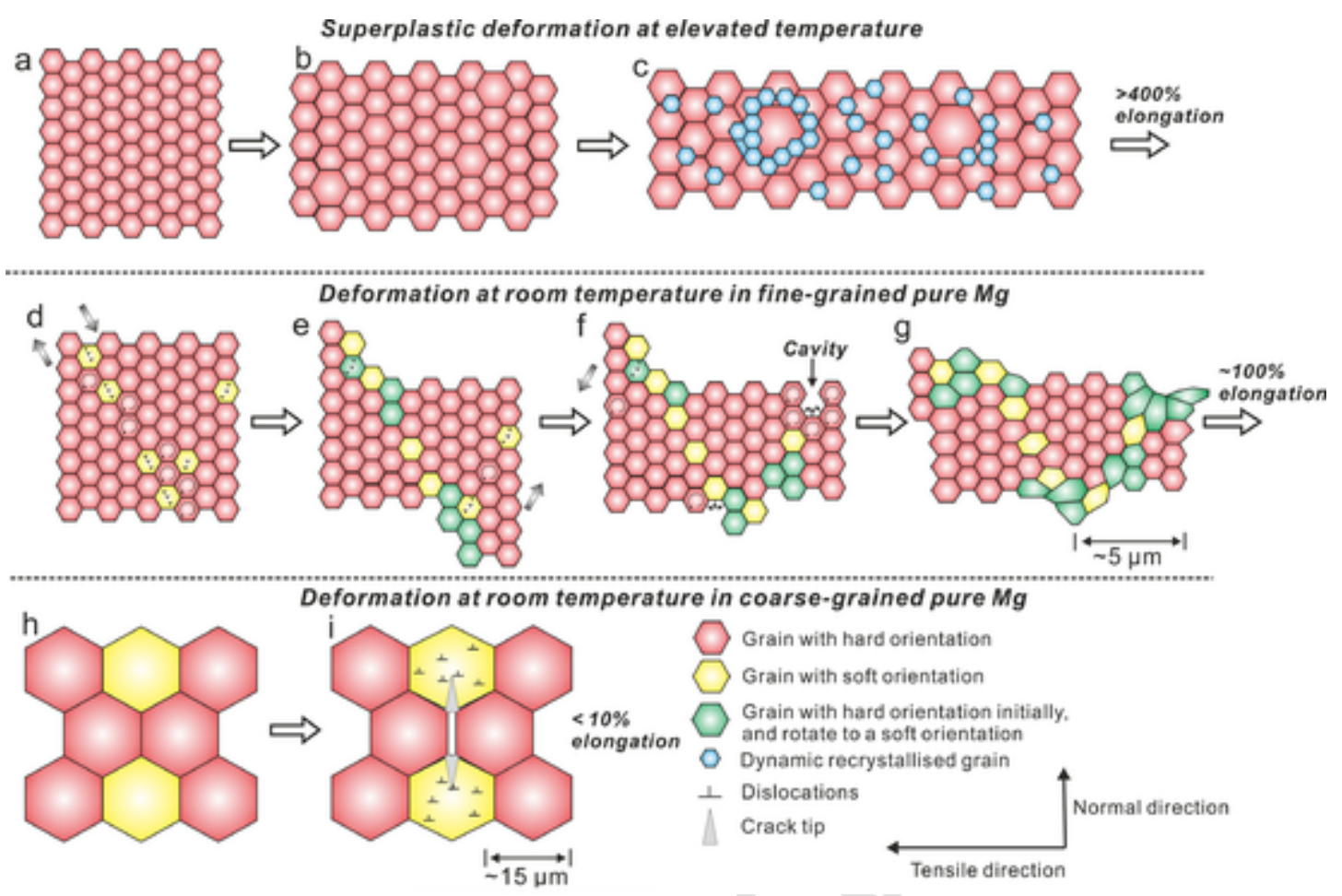

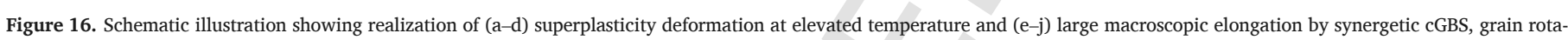
tion and intra-granular deformation in FG-Mg, and $(\mathrm{k}, \mathrm{l})$ low ductility in CG-Mg.

ing mechanism is a key factor that guarantees the high ductility. For metals that exhibit superplasticity in general, the accommodation modes include diffusion, extensive grain boundary migration, dynamic recrystallization, and dislocation slip [35, 36]. However, as aforementioned in 4.1, the in-situ TEM observations rule out the possibility of grain boundary migration in FG-Mg as the accommodation mode. This is different from the accommodated achieved by mobile grain boundaries in nanocrystalline metals at room temperature [67-69]. Due to the lack of mobile grain boundary, the discontinuous dynamic recrystallization and growth of recrystallized grains [70], which requires the migration of the grain boundaries, is not likely to occur during the deformation herein.

With respect to diffusion, it is not observed by using in-situ electron microscopy or X-ray diffraction. Moreover, deformation via diffusion during stretching normally needs high temperature [71], which should be far higher than room temperature for pure $\mathrm{Mg}$. Moreover, the strain rate sensitivity value will be close to unity if the diffusional flow is the mechanism [35]. Therefore, the diffusional flow is unlikely to be a major accommodation mode to the $c \mathrm{GBS}$ of $\mathrm{Mg}$ at room temperature.

Having established that diffusion, grain boundary migration, dynamic recrystallization are unlikely to be the accommodation mode, the only possible accommodation mode to the $c \mathrm{GBS}$ is dislocation slip. Dislocation slip was regarded as a minor accommodation mechanism for GBS during superplastic deformation $[35,36]$. The experimental observations herein, however, demonstrate active operation of dislocation slip, which rationalises the $m$-value of $\sim 0.2$ rather than $\sim 0.5$. Empirically, the higher activity of dislocation slip results in a lower $m$-value [24]. The significant operation of dislocation slip is found critical to effectively accommodate $c$ GBS. To accommodate $c$ GBS, the magnitude of intra-granular deformation is found to be surprisingly large in some grains, which is distinctly different to the conventional opinion that $\mathrm{Mg}$ is intrinsically difficult to be intra-granularly deformed at room temperature. Hence, the next question is how some grains in pure $\mathrm{Mg}$ can be deformed to such a large extent by intra-granular deformation?
This question is addressed here by utilising the multiple-length scale in-situ characterization approach. A major reason for the low ductility in $\mathrm{Mg}$ is that dislocations are prone to entangle within the grains, and they thereafter become obstacles that further impede the motion of mobile dislocation, leading to high hardening and low ductility [3]. However, in the present study, the in-situ TEM observations reveal that dislocations can be absorbed by grain boundaries (Supplementary videos 2, 3 , and 5). Therefore, effective dynamic recovery is proposed to operate in FG-Mg by dislocation annihilation at the grain boundaries, similar to those reported in other fine-grained metals [72-74]. In the FG-Mg, the density of the grain boundary was $\sim 300 \mu \mathrm{m} / \mu \mathrm{m}^{2}$, which is almost 10 times higher than that in the CG-Mg of $\sim 30 \mu \mathrm{m} / \mu \mathrm{m}^{2}$ (measured from the EBSD result in Fig. 1). Therefore, with fewer dislocation pile-ups, mobile dislocations are less likely to be impeded, leading to a lower strain hardening and contributing to a higher ductility. The speculation of recovery is further validated by in-situ synchrotron observations. The peak broadening in the FG-Mg is much slower than that in the CG-Mg and reaches a plateau after $\sim 6 \%$ elongation. In contrast, in the CG-Mg, the rapid broadening occurs in all peaks and there is no plateau formation, demonstrating that the dislocation annihilation mechanism does not effectively operate when the grain size is large $(\sim 12 \mu \mathrm{m}$ in average). The resultant high density of dislocations may result in great difficulty in dislocation motion, which becomes an important factor for the high hardening and low ductility in coarse grains.

The accommodation to substantial strain caused by cGBS is further enhanced by the rotation of grains located between slid grouped grains, from hard to softer orientations to allowing dislocation slip to readily occur (Figs. 16d-f). With the aid of grain rotation, the amount of grains that are expected to actively participate into accommodating $c$ GBS is increased, so that the deformation of the shear band becomes diffused, rather than localised. These coordinated deformation processes greatly postpone the occurrence of localised stress concentration during stretching.

The accommodation by combined processes of rotation and dislocation slip is so effective that even cavities, which inevitably form due to 
the incompatibility between the different slid grouped grains, are difficult to grow (Fig. 16f). The intra-granular deformation of grains adjacent to cavities can be so significant that it even flattens the cavities during further tensile deformation (Figs. 16f and g). Therefore, although the cavities are formed at the early stage of $c \mathrm{GBS}$, they are difficult to grow, and thus unlikely to affect the sample ductility. This is similar to the case of Ti-Al-based dual-phase alloys, in which the ductile $\beta$ phase suppresses the crack propagation and enhances ductility [75]. In contrast, in CG-Mg, grains also tend to move against each other. However, the grains are rigid: Grains cannot rotate or slide, as there is no mechanism that can accommodate their relative motion. Consequently, local cracks along the grain boundaries are formed, and then there is no mechanism to prevent the propagation of local cracks (Figs. 16h and i). As illustrated, they readily propagate through several grains, resulting in fracture at small elongation and the smooth fracture surface.

In this study, significant intra-granular deformation of some grains was demonstrated through in-situ SEM and in-situ TEM, however there still remains a lack of direct evidence in regards to demonstrating what type of dislocations contribute to outstanding ductility. We posited that basal dislocation slip might play a dominant role, due to the lower critical shear stress (CRSS) than other dislocation modes. At room temperature, the CRSS value is $57 \mathrm{MPa}$ for pyramidal dislocation slip and 39 MPa for prismatic dislocation slip, about an order higher than the CRSS for basal dislocation slip of $4 \mathrm{MPa}$ [76]. Despite the much higher CRSS, it is still possible that in grains with hard orientation throughout tensile stretching, non-basal dislocation slip still actively operates and contributes to ductility. Moreover, it has been observed that $\langle\mathrm{c}+\mathrm{a}\rangle$ dislocations can also migrate in pure $\mathrm{Mg}$ single crystals [6], when they are deformed along hard orientation (e.g. compression along the $c$-axis of crystal). How non-basal dislocation slip contributes to the high ductility of fine-grained pure $\mathrm{Mg}$ polycrystalline will require investigation in a future study.

\section{Conclusions}

The present study reveals that fine-grained $\mathrm{Mg}$ is extraordinarily ductile at room temperature, exhibiting an elongation of $\sim 100 \%$ at a strain rate of $10^{-4} / \mathrm{s}$ and more than $200 \%$ at $10^{-5}$. A set of complementary in-situ characterisation techniques, including in-situ synchrotron X-ray diffraction, SEM, DIC, EBSD, and TEM characterisation, were utilised to provide direct evidences that reveal the operating deformation mode in the fine-grained pure $\mathrm{Mg}$. The main conclusions are:

a In-situ synchrotron X-ray diffraction reveals that grain size has a significant influence on the evolution of elastic lattice strain and peak broadening during tensile deformation. When the grain size is $\sim 1.2$ $\mu \mathrm{m}$, the accumulation of elastic lattice strain and micro-strain in bulk FG-Mg is 3-10 times lower than that in the CG-Mg with an average grain size of $\sim 12 \mu \mathrm{m}$. The remarkably low strain observed in the FG-Mg grains suggests the operation of an inter-granular deformation mode that is different from the intra-granular deformation operated in the CG-Mg.

b In-situ SEM-based techniques reveal that the inter-granular deformation in FG-Mg occurs predominantly by relative sliding between grouped grains with similar basal orientations. The strain within grouped grains is limited in spite of the operation of GBS there. In contrast, the strain resulting from the sliding between grouped grains is substantial, and is accommodated mostly by rotation of grains located between slid grouped grains, from hard to softer orientations to allowing dislocation slip to more readily occur. These coordinated sliding and accommodation processes are absent in the CG-Mg during tensile deformation.

c In-situ TEM observation exhibits mobile dislocations and immobile grain boundaries, and demonstrates that mobile dislocations glide readily to and annihilate at grain boundaries. With denser grain boundaries in the FG-Mg than CG-Mg, the mobile dislocations have a higher probability to be absorbed by grain boundaries, and are thus less likely to be entangled with other intra-granular dislocations. The observed dislocation motion and annihilation rationalises the plateau formed in the synchrotron FWHM data, which both demonstrate an effective recovery in the FG-Mg during tensile deformation.

d In the FG-Mg, although cavities are formed because of the incompatibility during grain sliding, they are often healed by the intra-granular deformation of adjacent grains during further elongation, and therefore they are unlikely to affect bulk sample ductility. In contrast, in the CG-Mg, grains also tend to move against each other, but these coarse grains are difficult to rotate, slide or deform. The relative grain motion results in tearing at the grain boundary, which readily transforms into open cracks.

e The dominant deformation mode of pure $\mathrm{Mg}$ is strongly dependent on grain size. When the $\mathrm{Mg}$ grain size is reduced to the order of one micron, the major deformation mode is altered from dislocation slip to sliding between grouped grains that is accommodated by grain rotation and dislocation slip. These coordinated deformation and accommodation processes postpone the occurrence of localised stress concentration and greatly increases the ductility of pure $\mathrm{Mg}$ at room temperature.

\section{Declaration of Competing Interest}

The authors declare that they have no known competing financial interests or personal relationships that could have appeared to influence the work reported in this paper.

\section{Acknowledgements}

We gratefully acknowledge the infrastructure at the Monash Centre of Electron Microscopy and the Australian Synchrotron, ANSTO (Powder Diffraction beamline). Funding for this work includes support from the Australian Research Council, Baosteel Co., the Swedish Research Council and the Royal Swedish Academy of Engineering Sciences. The authors acknowledge discussions with Kailing Tang, Jun Wang, Sitamara Kada, Nick Armstrong, Justin Kimpton, and Yves Brechet.

\section{Supplementary materials}

Supplementary material associated with this article can be found, in the online version, at doi:10.1016/j.actamat.2021.116648.

\section{References}

[1] T.M. Pollock, Weight loss with magnesium alloys, Science 328 (5981) (2010) 986-987.

[2] W.J. Joost, P.E. Krajewski, Towards magnesium alloys for high-volume automotive applications, Scripta Mater 128 (2017) 107-112.

[3] Z. Wu, W.A. Curtin, The origins of high hardening and low ductility in magnesium, Nature 526 (7571) (2015) 62-67.

[4] I. Polmear, D. StJohn, J.F. Nie, M. Qian, Light Alloys, Fifth Edition, Butterworth-Heinemann, Boston, 2017.

[5] G.I. Taylor, Plastic strain in metals, J Inst Metal 62 (1938) 307-338.

[6] B.Y. Liu, F. Liu, N. Yang, X.-B. Zhai, L. Zhang, Y. Yang, B. Li, J. Li, E. Ma, J.F. Nie, Z.-W. Shan, Large plasticity in magnesium mediated by pyramidal dislocations, Science 365 (6448) (2019) 73-75.

[7] C.M. Cepeda-Jiménez, J.M. Molina-Aldareguia, M.T. Pérez-Prado, Effect of grain size on slip activity in pure magnesium polycrystals, Acta Mater $84(0)$ (2015) 443-456.

[8] Z.R. Zeng, N. Stanford, C.H.J. Davies, J.F. Nie, N. Birbilis, Magnesium extrusion alloys: a review of developments and prospects, Int Mater Rev (2018) 1-36.

[9] Z.R. Zeng, M.Z. Bian, S.W. Xu, C.H.J. Davies, N. Birbilis, J.F. Nie, Effects of dilute additions of $\mathrm{Zn}$ and $\mathrm{Ca}$ on ductility of magnesium alloy sheet, Mater Sci Eng A 674 (2016) 459-471.

[10] Z. Wu, R. Ahmad, B. Yin, S. Sandlöbes, W.A. Curtin, Mechanistic origin and prediction of enhanced ductility in magnesium alloys, Science 359 (6374) (2018) 447-452. 
[11] S. Yi, J. Bohlen, F. Heinemann, D. Letzig, Mechanical anisotropy and deep drawing behaviour of AZ31 and ZE10 magnesium alloy sheets, Acta Mater 58 (2) (2010) 592-605.

[12] B.C. Suh, M.S. Shim, K.S. Shin, N.J. Kim, Current issues in magnesium sheet alloys: Where do we go from here?, Scripta Mater 84-85 (0) (2014) 1-6.

[13] Y. Chino, T. Ueda, Y. Otomatsu, K. Sassa, X. Huang, K. Suzuki, M. Mabuchi, Effects of $\mathrm{Ca}$ on tensile properties and stretch formability at room temperature in Mg-Zn and Mg-Al alloys, Mater Trans 52 (7) (2011) 1477-1482.

[14] J. Hirsch, T. Al-Samman, Superior light metals by texture engineering: Optimized aluminum and magnesium alloys for automotive applications, Acta Mater 61 (3) (2013) 818-843.

[15] Z.R. Zeng, Y.M. Zhu, S.W. Xu, M.Z. Bian, C.H.J. Davies, N. Birbilis, J.F. Nie, Texture evolution during static recrystallization of cold-rolled magnesium alloys, Acta Mater 105 (2016) 479-494.

[16] Z.R. Zeng, J.F. Nie, S.W. Xu, C.H.J. Davies, N. Birbilis, Super-formable pure magnesium at room temperature, Nature Communications 8 (1) (2017) 972

[17] H. Somekawa, A. Singh, R. Sahara, T. Inoue, Excellent room temperature deformability in high strain rate regimes of magnesium alloy, Scientific Reports 8 (1) (2018) 656.

[18] H. Somekawa, T. Mukai, Hall-Petch breakdown in fine-grained pure magnesium at low strain rates, Metall Mater Trans A 46 (2) (2015) 894-902.

[19] H. Somekawa, A. Singh, Superior room temperature ductility of magnesium dilute binary alloy via grain boundary sliding, Scripta Mater 150 (2018) 26-30.

[20] H. Somekawa, D.A. Basha, A. Singh, Room temperature grain boundary sliding behavior of fine-grained Mg-Mn alloys, Mater Sci Eng A 730 (2018) 355-362.

[21] H. Somekawa, A. Kinoshita, A. Kato, Great room temperature stretch formability of fine-grained Mg-Mn alloy, Mater Sci Eng A 697 (2017) 217-223.

[22] R.B. Figueiredo, S. Sabbaghianrad, A. Giwa, J.R. Greer, T.G. Langdon, Evidence for exceptional low temperature ductility in polycrystalline magnesium processed by severe plastic deformation, Acta Mater 122 (2017) 322-331.

[23] R.B. Figueiredo, F.S.J. Poggiali, C.L.P. Silva, P.R. Cetlin, T.G. Langdon, The influence of grain size and strain rate on the mechanical behavior of pure magnesium, J Mater Sci 51 (6) (2016) 3013-3024.

[24] T.G. Langdon, Seventy-five years of superplasticity: historic developments and new opportunities, J Mater Sci 44 (22) (2009) 5998-6010.

[25] C.E. Pearon, The viscous properties of extruded eutectic alloys of lead-tin and bismuth-tin, J Inst. Metals 54 (1934) 111.

[26] R.S. Mishra, R.Z. Valiev, A.K. Mukherjee, The observation of tensile superplasticity in nanocrystalline materials, Nanostruct Mater 9 (1) (1997) 473-476.

[27] M.M.I. Ahmed, T.G. Langdon, Ductility of the superplastic Pb-Sn eutectic at room temperature, J Mater Sci Lett 2 (2) (1983) 59-62.

[28] R. Gifkins, Superplasticity during creep, J Inst Metals 95 (12) (1967) 373-377.

[29] E. Mostaed, M.S. Ardakani, M. Sikora-Jasinska, J.W. Drelich, Precipitation induced room temperature superplasticity in $\mathrm{Zn}-\mathrm{Cu}$ alloys, Mater Lett 244 (2019) 203-206.

[30] M. Demirtas, G. Purcek, H. Yanar, Z.J. Zhang, Z.F. Zhang, Effect of equal-channel angular pressing on room temperature superplasticity of quasi-single phase $\mathrm{Zn}-0.3 \mathrm{Al}$ alloy, Mater Sci Eng A 644 (2015) 17-24.

[31] L. Lu, M.L. Sui, K. Lu, Superplastic Extensibility of Nanocrystalline Copper at Room Temperature, Science 287 (5457) (2000) 1463-1466.

[32] L. Lu, M.L. Sui, K. Lu, Cold rolling of bulk nanocrystalline copper, Acta Mater 49 (19) (2001) 4127-4134.

[33] R.Z. Valiev, I.V. Alexandrov, Y.T. Zhu, T.C. Lowe, Paradox of strength and ductility in metals processed by severe plastic deformation, J Mater Res 17 (1) (2002) 5-8.

[34] S.X. McFadden, R.S. Mishra, R.Z. Valiev, A.P. Zhilyaev, A.K. Mukherjee, Low-temperature superplasticity in nanostructured nickel and metal alloys, Nature 398 (6729) (1999) 684-686.

[35] T.G. Nieh, Superplasticity in metals and ceramics, Cambridge University Press, Cambridge, 1997.

[36] A.H. Chokshi, A.K. Mukherjee, T.G. Langdon, Superplasticity in advanced materials, Mater Sci Eng R 10 (6) (1993) 237-274.

[37] K.S. Wallwork, B.J. Kennedy, D. Wang, The high resolution powder diffraction beamline for the Australian Synchrotron, AIP Conference Proceedings 879 (1) (2007) 879-882.

[38] B. Schmitt, C. Brönnimann, E.F. Eikenberry, F. Gozzo, C. Hörmann, R. Horisberger, B. Patterson, Mythen detector system, Nucl Instrum Meth A 501 (1) (2003) 267-272.

[39] J. Cline, R. Deslattes, J. Staudemann, E. Kessler, L. Hudson, A. Henis, R. Cheary, NIST Certificate-Standard Reference Material 640c, NIST Certificate-Standard Reference Material 660b (2000) 1-5.

[40] S.R. Kada, P.A. Lynch, J.A. Kimpton, M.R. Barnett, In-situ X-ray diffraction studies of slip and twinning in the presence of precipitates in AZ91 alloy, Acta Mater 119 (2016) 145-156.

[41] Z. Wang, P.A. Lynch, S.R. Kada, N. Armstrong, E.B. Motlagh, J.A. Kimpton, M.R. Barnett, A high-resolution synchrotron-based diffraction technique for in situ characterization of deformation behaviour in magnesium alloys, J Appl Crystallogr 51 (4) (2018) 1082-1093.

[42] C.J. Bettles, P.A. Lynch, A.W. Stevenson, D. Tomus, M.A. Gibson, K. Wallwork, J. Kimpton, In situ observation of strain evolution in cp-Ti Over multiple length scales, Metall Mater Trans A 42 (1) (2011) 100-110.

[43] P. Moeck, S. Rouvimov, E.F. Rauch, M. Véron, H. Kirmse, I. Häusler, W Neumann, D. Bultreys, Y. Maniette, S. Nicolopoulos, High spatial resolution semi-automatic crystallite orientation and phase mapping of nanocrystals in transmission electron microscopes, Cryst Res Technol 46 (6) (2011) 589-606.

[44] Bruker, TOPAS, Total Pattern Analysis Solutions, Bruker-AXS, Madison, WI, 2005.
[45] D. Balzar, Voigt-function model in diffraction line-broadening analysis, International union of crystallography monographs on crystallography 10 (1999) 94-126.

[46] E.W. Hart, Theory of the tensile test, Acta Metall 15 (2) (1967) 351-355.

[47] S.R. Kada, P.A. Lynch, M.R. Barnett, Development of a laboratory-based transmission diffraction technique for in situ deformation studies of $\mathrm{Mg}$ alloys, J Appl Crystallogr 48 (2) (2015) 365-376.

[48] O. Muránsky, D.G. Carr, P. Šittner, E.C. Oliver, In situ neutron diffraction investigation of deformation twinning and pseudoelastic-like behaviour of extruded AZ31 magnesium alloy, Int J Plasticity 25 (6) (2009) 1107-1127.

[49] R.L. Bell, T.G. Langdon, An investigation of grain-boundary sliding during creep, J Mater Sci 2 (4) (1967) 313-323.

[50] X. Wang, L. Jiang, D. Zhang, T.J. Rupert, I.J. Beyerlein, S. Mahajan, E.J. Lavernia, J.M. Schoenung, Revealing the deformation mechanisms for room-temperature compressive superplasticity in nanocrystalline magnesium, Materialia 11 (2020) 100731.

[51] F. Mompiou, D. Caillard, M. Legros, H. Mughrabi, In situ TEM observations of reverse dislocation motion upon unloading in tensile-deformed UFG aluminium, Acta Mater 60 (8) (2012) 3402-3414.

[52] F. Mompiou, M. Legros, A. Boé, M. Coulombier, J.P. Raskin, T. Pardoen, Interand intragranular plasticity mechanisms in ultrafine-grained Al thin films: An in situ TEM study, Acta Mater 61 (1) (2013) 205-216.

[53] H. Watanabe, T. Mukai, K. Ishikawa, Y. Okanda, M. Kohzu, K. Higashi, Superplastic characteristics in an extruded AZ31 magnesium alloy, J Japan Inst Light Metal 49 (8) (1999) 401-404.

[54] H. Watanabe, T. Mukai, M. Kohzu, S. Tanabe, K. Higashi, Effect of temperature and grain size on the dominant diffusion process for superplastic flow in an AZ61 magnesium alloy, Acta Mater 47 (14) (1999) 3753-3758.

[55] H. Watanabe, T. Mukai, K. Higashi, Superplasticity in a ZK60 magnesium alloy at low temperatures, Scripta Mater 40 (4) (1999) 477-484.

[56] M. Mabuchi, K. Ameyama, H. Iwasaki, K. Higashi, Low temperature superplasticity of AZ91 magnesium alloy with non-equilibrium grain boundaries, Acta Mater 47 (7) (1999) 2047-2057.

[57] M. Mabuchi, T. Asahina, H. Iwasaki, K. Higashi, Experimental investigation of superplastic behaviour in magnesium alloys, Mater Sci Tech 13 (10) (1997) 825-831.

[58] A. Bussiba, A. Ben Artzy, A. Shtechman, S. Ifergan, M. Kupiec, Grain refinement of AZ31 and ZK60 Mg alloys - towards superplasticity studies, Mater Sci Eng A 302 (1) (2001) 56-62.

[59] H. Watanabe, M. Fukusumi, Mechanical properties and texture of a superplastically deformed AZ31 magnesium alloy, Mater Sci Eng A 477 (1) (2008) 153-161.

[60] J. Koike, R. Ohyama, T. Kobayashi, M. Suzuki, K. Maruyama, Grain-boundary sliding in AZ31 magnesium alloys at room temperature to $523 \mathrm{~K}$, Mater Trans 44 (4) (2003) 445-451.

[61] O.A. Kaibyshev, A.I. Pshenichniuk, V.V. Astanin, Superplasticity resulting from cooperative grain boundary sliding, Acta Mater 46 (14) (1998) 4911-4916.

[62] V.V. Astanin, O.A. Kaibyshev, S.N. Faizova, Cooperative grain boundary sliding under superplastic flow, Scripta Metall Mater 25 (12) (1991) 2663-2668.

[63] M.G. Zelin, N.A. Krasilnikov, R.Z. Valiev, M.W. Grabski, H.S. Yang, A.K. Mukherjee, On the microstructural aspects of the nonhomogeneity of superplastic deformation at the level of grain groups, Acta Metall Mater 42 (1) (1994) 119-126.

[64] A. Vinogradov, S. Hashimoto, V. Patlan, K. Kitagawa, Atomic force microscopic study on surface morphology of ultra-fine grained materials after tensile testing, Mater Sci Eng A 319-321 (2001) 862-866.

[65] I. Sabirov, Y. Estrin, M.R. Barnett, I. Timokhina, P.D. Hodgson, Tensile deformation of an ultrafine-grained aluminium alloy: Micro shear banding and grain boundary sliding, Acta Mater 56 (10) (2008) 2223-2230.

[66] M.G. Zelin, A.K. Mukherjee, Cooperative phenomena at grain boundaries during superplastic flow, Acta Metall Mater 43 (6) (1995) 2359-2372.

[67] Z. Shan, E.A. Stach, J.M.K. Wiezorek, J.A. Knapp, D.M. Follstaedt, S.X. Mao, Grain boundary-mediated plasticity in nanocrystalline nickel, Science 305 (5684) (2004) 654-657.

[68] K. Lu, Stabilizing nanostructures in metals using grain and twin boundary architectures, 1 (2016) 16019.

[69] X. Zhou, X. Li, K. Lu, Size dependence of grain boundary migration in metals under mechanical loading, Phys Rev Lett 122 (12) (2019) 126101

[70] Q. Liu, X.X. Huang, M. Yao, J.F. Yang, On deformation-induced continuous recrystallization in a superplastic Al-Li-Cu-Mg-Zr alloy, Acta Metall Mater 40 (7) (1992) 1753-1762.

[71] C. Herring, Diffusional viscosity of a polycrystalline solid, J Appl Phys 21 (5) (1950) 437-445.

[72] M.W. Grabski, R. Korski, Grain boundaries as sinks for dislocations, Phil Mag A 22 (178) (1970) 707-715

[73] X. Huang, N. Hansen, N. Tsuji, Hardening by annealing and softening by deformation in nanostructured metals, Science 312 (5771) (2006) 249-251.

[74] S. Ni, Y.B. Wang, X.Z. Liao, S.N. Alhajeri, H.Q. Li, Y.H. Zhao, E.J. Lavernia, S.P. Ringer, T.G. Langdon, Y.T. Zhu, Grain growth and dislocation density evolution in a nanocrystalline Ni-Fe alloy induced by high-pressure torsion, Scripta Mater 64 (4) (2011) 327-330.

[75] K.S. Chan, Influence of microstructure on intrinsic and extrinsic toughening in an alpha-two titanium aluminide alloy, Metall Trans A 23 (1) (1992) 183-199.

[76] J.F. Nie, K.S. Shin, Z.R. Zeng, Microstructure, Deformation, and Property of Wrought Magnesium Alloys, Metall Mater Trans A 51 (12) (2020) 6045-6109. 